IZA DP No. 9206

Agricultural Extension and Technology Adoption for Food Security: Evidence from Uganda

Yao Pan

Stephen C. Smith

Munshi Sulaiman

July 2015 


\title{
Agricultural Extension and Technology Adoption for Food Security: Evidence from Uganda
}

\author{
Yao Pan \\ Aalto University \\ Stephen C. Smith \\ George Washington University and IZA \\ Munshi Sulaiman \\ Yale University \\ Discussion Paper No. 9206 \\ July 2015 \\ IZA \\ P.O. Box 7240 \\ 53072 Bonn \\ Germany \\ Phone: +49-228-3894-0 \\ Fax: +49-228-3894-180 \\ E-mail: iza@iza.org
}

\begin{abstract}
Any opinions expressed here are those of the author(s) and not those of IZA. Research published in this series may include views on policy, but the institute itself takes no institutional policy positions. The IZA research network is committed to the IZA Guiding Principles of Research Integrity.

The Institute for the Study of Labor (IZA) in Bonn is a local and virtual international research center and a place of communication between science, politics and business. IZA is an independent nonprofit organization supported by Deutsche Post Foundation. The center is associated with the University of Bonn and offers a stimulating research environment through its international network, workshops and conferences, data service, project support, research visits and doctoral program. IZA engages in (i) original and internationally competitive research in all fields of labor economics, (ii) development of policy concepts, and (iii) dissemination of research results and concepts to the interested public.
\end{abstract}

IZA Discussion Papers often represent preliminary work and are circulated to encourage discussion. Citation of such a paper should account for its provisional character. A revised version may be available directly from the author. 


\section{ABSTRACT \\ Agricultural Extension and Technology Adoption for Food Security: Evidence from Uganda*}

This paper evaluates causal impacts of a large-scale agricultural extension program for smallholder women farmers on food security in Uganda through a regression discontinuity design that exploits an arbitrary distance-to-branch threshold for village program eligibility. We find eligible farmers experienced significant increases in agricultural production, savings and wage income, which lead to improved food security. Given minimal changes in the adoption of relatively expensive inputs including HYV seeds, these gains are mainly attributed to increased usage of improved cultivation methods that are relatively costless. These results highlight the role of improved basic methods in boosting agricultural productivity among poor farmers.

JEL Classification: $\quad$ O13, Q12, I30

Keywords: agriculture, extension, agricultural technology adoption, food security, regression discontinuity, Uganda, labor markets in developing economies

Corresponding author:

Stephen C. Smith

Department of Economics

Monroe Hall 306 (2115 G St. NW)

George Washington University

Washington, D.C. 20052

USA

E-mail: ssmith@gwu.edu

\footnotetext{
* We would like to thank Michael Carter, Ram Fishman, Craig Macintosh, and participants at the BASIS Annual Technical Committee Meeting workshop, George Washington University, November 2014, CSAE 2014, and seminars at Aalto University and GWU for helpful comments on an early draft of this paper. Special thanks to Proloy Barua, M. Mozammel Huq, and Hannan Ali of BRAC Uganda for their assistance with field visits, data and many helpful discussions about the program. All errors are our own. This paper is part of the project on "Complementarities of Training, Technology, and Credit in Smallholder Agriculture: Impact, Sustainability, and Policy for Scaling-up in Senegal and Uganda," funded by BASIS, whose support is gratefully acknowledged.
} 


\section{INTRODUCTION}

The recent development economics literature has focused on the need to address fundamental constraints in moving out of poverty in general and improving performance of low-productivity smallholder agriculture in particular. Many proven technologies and improved farming practices hold great promise for boosting agricultural production and reducing poverty in developing countries, but the adoption of such technologies by smallholder farmers, in particular in Sub Saharan Africa, has been slow, at best (Udry, 2010; Duflo, Kremer \& Robinson, 2011). The low adoption rates resulted in persistent low agricultural productivity in Sub Saharan Africa (Bank, 2008). Important identified culprits in low adoption include lack of knowledge, lack of access to markets, credit constraints, uninsured risks, and problems of coordination with neighbors (Bank, 2008; Udry, 2010; Barrett, Carter \& Timmer, 2010; Jack, 2013). Most research along this line focuses on the adoption of expensive agricultural inputs, such as high yield variety (HYV) seeds and chemical fertilizers. However, there are few analyses of initial adoption and the impacts of improved basic cultivation methods.

This paper contributes to filling this gap by evaluating the impacts of an innovative large-scale agricultural extension program for smallholder women farmers in Uganda on their technology adoption and food security. The program, designed by the NGO BRAC, features two main components to promote improved technology use: training, conducted by Model Farmers; and easier access to, and affordability of, HYV seeds sold through farmers serving as Community Agriculture Promoters (CAPs). According to the program design, eligibility for this program is limited to villages within $6 \mathrm{~km}$ to the nearest BRAC branch office, allowing us to analyze the intention-to-treat effects under a regression discontinuity design (RDD) framework. Using agriculture survey data from over 3000 households near the distance threshold, we estimate the effect of program eligibility at village level on individual 
households' food security, which includes possible within-village spillover effects. In addition, detailed inputs usage and farming practices information are reported, providing us the potential to separate the effect of improvement in farming methods from input changes in promoting production and food security.

Results for food security are dramatic. For farmers residing in eligible villages, per capita household food consumption increased by about $17.1 \%$ compared with farmers residing in ineligible villages; and the likelihood of having sufficient food for family needs increased by 28 percentage points over the previous year. Moreover, while the program increased the proportion of households with sufficient food every month in the year prior to the survey, impacts are largest just before the harvest, when food security is generally most precarious. In the month leading up to the survey, households eligible for the program were 10.6 percentage points less likely to worry about insufficient food, 8.2 percentage points less likely to limit consumption varieties, 9.5 percentage points less likely to consume limited portions of food at each meal, and 14 percentage points less likely to skip meals. Among the $54 \%$ of households that experienced at least one village shock - drought, flood, pest attack, livestock epidemic, fire, or poor quality seeds - in the 6 months prior to the survey, households eligible for the program were 14 percentage points more likely to cope by using savings; and 6.5 percentage points less likely to respond by begging. Finally, with potential longer-term benefits, treatment households were 11.4 percentage points more likely to reduce consumption and 5.4 percentage points less likely to sell assets during shocks. Together, these results confirm the positive impact of the extension program on improved food security.

In terms of mechanisms, we find the agricultural extension services significantly increase the usage of improved cultivation methods that are relatively costless. Farmers residing in eligible villages are 4.5 percentage points more likely to use manure (organic fertilizer) and 2.8 percentage points more likely to irrigate their 
land compared with those residing in ineligible villages. Being eligible for the program also increases farmers' adoption rate of intercropping and crop rotation by 6 and 5.4 percentage points, respectively. All these practices have been documented to mitigate soil erosion and increase yields (Liniger et al., 2011). Interestingly, the adoption rate of improved seeds remains unchanged regardless of advocacy in training sessions, improved access, and supply side subsidy. Seed purchase from BRAC does increase by 5.7 percentage points, though, suggesting crowding out of the local supply, although BRAC seeds could be of higher quality than existing market seeds. ${ }^{1}$ In addition, the extension program does not change the adoption rate of other costly agricultural inputs, such as chemical fertilizer and pesticides. Given unchanged usage of advanced inputs, the findings of improved food security are likely to be driven by changes in farming methods. ${ }^{2}$

Unlike most papers in the literature that examine the adoption of expensive inputs and new crops (Munshi, 2004; Bandiera \& Rasul, 2006; Conley \& Udry, 2010; Krishnan \& Patnam, 2014), this paper focuses on cultivation methods that require low upfront monetary investment. While some existing studies have documented the effect of agricultural training on the adoption of improved cultivation methods (Kondylis, Mueller \& Zhu, 2014) or production outcomes (Godtland et al., 2003; Mutandwa \& Mpangwa, 2004; Davis et al., 2012), few focus on both at the same time and provide rigorous causal evaluation of the yield-improving impact of these methods in the field. Our paper fills this critical gap by analyzing the causal effect of agriculture training on adoption of improved farming methods and the resulting impact on production and food security in a quasi-experimental RDD framework.

\footnotetext{
${ }^{1}$ We do not have data on the relative quality of BRAC seeds and other HYV seeds available on the general market.

${ }^{2}$ The agriculture training may promote other productive farming methods/knowledge than the ones examined here, such as timing and dosage of fertilizer use and diagnostic of pests. However, these additional aspects are not covered by the survey.
} 
Importantly, the data allow us to separate the effect of these inexpensive farming methods from costly inputs. Agricultural training may encourage advanced input usage in addition to promoting improved cultivation methods. As noted by Herdt (2010), separating different factors in integrated agricultural production has been a difficult challenge for understanding the contribution of each factor. In our study, the extension program hardly has any impacts on advanced inputs usages and total input purchase costs. Even though the effect of each cultivation method is hard to identify individually, the overall changes in farming methods alone have a significant positive impact on production and food security. These farming methods require low upfront monetary investment and have fewer adoption constraints compared to more expensive advanced inputs. Hence, this paper provides important insights on the dynamics of agriculture extension provision. The adoption of relatively inexpensive methods in the first place boosts farmers' agricultural production and savings. The farmers' subsequently improved economic status may in turn relax constraints on advanced inputs adoption in the future.

This paper also contributes to the agricultural extension literature by examining the impact on detailed measures of food security and shock-coping methods. Most research to date has focused on advanced input adoption and production; few papers have assessed extension achievements in more comprehensive domains (Anderson \& Feder, 2007). Our paper covers essential aspects of food security noted by Barrett (2002): quantitative availability, qualitative aspects concerning types and diversity of food, psychological dimensions relating to feelings of deprivation or anxiety related to food availability, and social consumption patterns such as meal frequency. To the best of our knowledge, this is the first paper to analyze the impacts of agricultural extension on food security in such a comprehensive way. In addition, improved economic status for households exposed to the agricultural program may further lead to changes in shock-coping behaviors, which serve as additional measures of food security status. In particular, we find that, with improved economic status, eli- 
gible households are more likely to reduce consumption and less likely to sell asset in the face of covariate shocks. These findings add new empirical evidence on the choice between consumption smoothing and asset smoothing in the face of shocks and confirms the heterogenous response across farmers' wealth levels (Zimmerman \& Carter, 2003; Carter \& Lybbert, 2012; Janzen \& Carter, 2013).

The rest of this paper is structured as follows: Section 2 provides background on agriculture practices in Uganda, introduces the project design, and describes the main data source used in this study. Section 3 presents the empirical strategy. Regression results and discussions are provided in Section 4. Section 5 concludes.

\section{CONTEXT AND DATA}

Agriculture plays an important role in the Ugandan Economy, accounting for $73 \%$ of employment, $50 \%$ of household income, and 21\% of GDP (UBOS, 2006, 2007, 2010). Despite the importance of agriculture, its growth is slow and subsistence farming is still prevalent in Uganda. Subsistence farmers account for $71 \%$ of the total farmers in the country. The adoption rates of advanced agricultural inputs and cultivation methods remain relatively low (UBOS, 2006, 2007).

Launched in August 2008, BRAC's large-scale agriculture program in Uganda seeks to improve food security of smallholders by promoting the usage of HYV seeds, mainly maize ${ }^{3}$, and improved farming methods. Adoption of these technology are expected to improve productivity of smallholder women farmers for greater food security, and not necessarily increase revenue from crop productions as agribusinesses. This program provides extension services and supports a network of

\footnotetext{
${ }^{3}$ Bean and vegetable seeds were also made available for purchase, though only about $10-20 \%$ of total value of seeds distributed were non-maize items.
} 
Model Farmers and Community Agriculture Promoters (CAP). The program operates 60 branches $^{4}$ in 41 districts in Uganda (Poghosyan, 2011), engages 1200 Model Farmers and reaches 63,936 general farmers by June 2011. Both types of agriculture extension workers are selected from villages within an arbitrary radius of $6 \mathrm{~km}^{5}$ from BRAC branches according to the program design, which allows us to study the impact of BRAC's agricultural program in a regression discontinuity design framework.

Model Farmers were selected by BRAC from among poor, marginalized women. They are similar to their neighbors in terms of farm size and input use, though slightly more progressive and were chosen from those with some education. They received six days of training in crop production techniques, adoption of new crop varieties and pest control, as well as follow-up refresher courses. Then, they were made responsible for setting up a demonstration plot using learned techniques and providing a three-day training activity for fifty other ("general") farmers in their villages. They received a small compensation, in the form of $10 \mathrm{~kg}$ HYV seeds, for each season in service, which were to be used for demonstration purposes on their farms. ${ }^{6}$ Each Model Farmer was expected to train fifty general farmers in total. All training sessions recommended the usage of improved farming methods and HYV seeds.

Community Agriculture Promoters (CAPs) were also selected from the same populations; their role is to make available and sell advanced agricultural inputs in the villages, mainly HYV seeds (Barua, 2011). They received the inputs at a modestly subsidized price of 2600 Ugandan Shillings (USh) per kg, which is around 10\%

\footnotetext{
${ }^{4}$ Branch location is primarily determined by BRAC's microfinance program, which was launched before the agricultural program. Thus BRAC branch offices tend to locate in trading centers and are proximate to banks.

${ }^{5}$ As documented in BRAC's office memos, the main reason for choosing $6 \mathrm{~km}$ at the cutoff distance was that the field officers can travel this distance on foot or by bicycle.

${ }^{6}$ In another context, BenYishay \& Mobarak (2014) show that peer farmers with compensation are more effective in convincing other farmers to adopt technologies as compared to lead farmers and government-employed extension workers.
} 
lower than the market price of 2800-3000 USh, then set their own price to resell to the general public. Compared to direct purchase subsidy, this design aims to improve entrepreneur skills of the CAPs, and help build up the local supply chain so it reaches the village level. The transfer of subsidized price to general farmers is not guaranteed.

The data used in this study come from BRAC's 2011 agriculture survey. There are two cropping seasons each year. The survey covers demographic information and detailed agricultural practices records for the previous two cropping seasons between July 2010 and June 2011. Figure 1 shows the surveyed counties in Uganda. The survey villages are identified within the program receiving counties. 17 villages were randomly selected from a complete village list in each county. Then, 25 households were randomly selected from the chosen villages (Barua, 2011). According to summary statistics for the main estimation sample presented in Table 1, modern techniques adoption rates are low in general and food security is far from being achieved.

\section{EMPIRICAL STRATEGY}

\subsection{Estimation Specifications}

As described in Section 2, households' eligibility for the program depends on their villages' distance to the nearest BRAC branch offices. This feature allows us to analyze the impacts of the program using regression discontinuity design.

As the extension activities were not reported beyond six months prior to the survey, we are unable to construct either an indicator of ever received training for each household or a precise measure of the village-level implementation of the pro- 
gram, such as an indicator of program coverage or the fraction of farmers ever received training in the village. ${ }^{7}$ Instead, we focus on the intention-to-treat impact of the planned program eligibility at village level on farming technology adoption and food security of households residing in these villages. Although the distance from village centers to the nearest BRAC branch was not directly reported, using GPS coordinates for each household and each branch, we compute the household's distance to the closest BRAC branch and use the median household distance in a village as a proxy to village distance. ${ }^{8}$

We use the nonparametric approach proposed by Hahn, Todd \& Van der Klaauw (2001) and Porter (2003) to estimate the treatment effects, which relaxes functional form assumptions in parametric regressions. This method estimates the left and right limits of an outcome variable and a treatment variable using local linear regression and then takes the difference of these two limits. The causal effects of the agricultural program on outcomes $\tau$ are given by:

$$
\tau_{a g}=\lim _{z \rightarrow c_{a g}^{-}} E\left[y_{i} \mid z_{i}=z\right]-\lim _{z \rightarrow c_{a g}^{+}} E\left[y_{i} \mid z_{i}=z\right]
$$

where $y_{i}$ is an outcome variable of household $i, z_{i}$ is the distance between households i's residing village and the nearest BRAC branch, $c_{a g}$ is the cutoff distance, ${ }^{9}$ and $\tau_{a g}$ is the impact of the agriculture program on outcome variables. Standard errors are calculated using the delta method. We report our main results using a triangular kernel with a bandwidth of $2.16 \mathrm{~km}$. We follow Imbens \& Kalyanaraman (2012) to calculate this optimal bandwidth and also report results for bandwidths ranging from $1.5 \mathrm{~km}$ to $3.5 \mathrm{~km}$. Since the treatments are defined as the planned agricultural extension coverage in the village, the estimates can be inter-

\footnotetext{
${ }^{7}$ The average program intensity is about $41 \%$. This estimate is calculated using administrative data on the overall program outreach and the average village size.

${ }^{8}$ This method may introduce fuzziness around the cutoff if households are not uniformly distributed in the village.

${ }^{9}$ In the context of this study, $c_{a g}=6 \mathrm{~km}$.
} 
preted as intention-to-treat (ITT) effects. These effects incorporate diffusion and spillover from treated households to other households in the village. ${ }^{10}$ As a robustness check, we also report results for main outcomes using parametric regressions, in which standard errors are clustered at the village level.

When interpreting the results, it should be kept in mind that the actual coverage can differ from the plan. Some eligible villages may be excluded while ineligible ones may participate due to imperfect compliance. If this is the case, the change in the program participation rate is less than one at the cutoff distance. Our main results therefore underestimate the impact of program participation estimated by "fuzzy" RD design that uses eligibility as an instrument for participation.

To show evidence of the discontinuity in the participation in the three-year agricultural program at the predetermined cutoff distance, we compile the limited information collected on extension activities in the six months proceeding the survey. We construct a village activities indicator that equals one if any surveyed households in this village ever received training from a Model Farmer or purchase seeds from a CAP in the last six months, and equals zero otherwise. We plot the proportion of households who live in villages with any program activity against their village distances to the nearest BRAC branch office in Figure 2. The curves show lowess fit to the left and right of the threshold. The visual evidence shows a clear decrease in the incidence of program activities in villages at the cutoff value of $6 \mathrm{~km}$.

Note that the training component of the program was implemented more intensively in the beginning of the program period because Model Farmers were only responsible to train up to fifty general farmers in their villages. Therefore, program activities in the six months proceeding the survey provides a somewhat noisy measure of program participation during the whole program period. The actual

\footnotetext{
${ }^{10}$ The estimation does not take into account possible spillover effect across villages. While BRAC's agriculture workers are restricted to work in certain areas, there may be information spillover effects through communication between farmers in nearby villages. Thus, the results reported in this study may underestimate the overall program effects.
} 
participation gap at the distance threshold is expected to be larger if the approximation error of the participation is of similar magnitude relative to the observed activity on each side of the threshold. With this limitation in mind, for robustness we also estimated the local average treatment effect of program activity by "fuzzy" $\mathrm{RD}$; in general, these estimates find a substantially larger program impact than our preferred specifications as reported here. ${ }^{11}$

\subsection{Validity of the $\mathrm{RD}$ design}

One concern of our approach is that ineligible households may move to program villages in order to participate in the program (Lee, 2008). In our sample, the migration rate is very low. Less than $2 \%$ households ever moved since the launch of the agricultural extension program (in the last three years). If households excluded from the program purposely moved closer to the branch in order to be eligible for the extension services, we would expect a spike in the households density right below the cutoff distance of $6 \mathrm{~km}$. Figure 3 plots the number of households in each 0.6 $\mathrm{km}$ bin against households' distance to the nearest BRAC branch. Visual evidence shows no noticeable jump in the density around the cutoff distance. The density smoothness test proposed by McCrary (2008) also fails to reject the smoothness of households' density at the cutoff.

Valid RD design requires that households are relatively similar over the cutoff, which can be partially tested by the balance of household characteristics. Thus, we check for possible jumps over the threshold for household heads' age, literacy, whether any household member holds positions in the village or higher-level committees, as well as possible discontinuity in the coverage of BRAC's microfinance program, which was operated in the same counties. Figure 4 graphically presents the mean value of each covariate in $0.6 \mathrm{~km}$ bins separately with a lowess fit. The visual evidence

\footnotetext{
${ }^{11}$ These results are reported in the online Appendix Table A7 to A10.
} 
shows no significant discontinuity within and beyond the cutoff distance for these variables. As suggested by Lee \& Lemieux (2010), we test the joint significance of all the discontinuities at the threshold in a Seemingly Unrelated Regression (SUR) framework, where each equation regresses one covariate on a threshold dummy, a constant and a fourth order polynomial of distance to the nearest BRAC branch office. The coefficients of polynomials are allowed to be different on each side of the threshold and errors are allowed to be correlated across equations. This test fails to reject the hypothesis that covariates are smooth across the cutoff for the agricultural program. ${ }^{12}$ We also add these control variables in the regression to further check the robustness of our results.

\section{RESULTS}

In this section, we first present the regression results on agricultural technology adoption. We then explore channels through which the agricultural program would affect food security and present results on food consumption and overall food security. At the end of this section, we examine changes in shock-coping methods.

\subsection{Adoption of basic techniques vs. advanced inputs}

We divide the examined technologies into two categories according to the upfront costs incurred during adoption. The inexpensive cultivation methods include manure usage $\mathrm{e}^{13}$, intercropping, crop rotation, irrigation ${ }^{14}$, and weeding. The advanced farming inputs are relatively more expensive, including HYV seeds, chemical fer-

\footnotetext{
${ }^{12}$ We also run the same local linear regressions for each of these control variables. None has statistically significant discontinuity at the program cutoff distance.

${ }^{13}$ We categorize manure as a farming method instead of an advanced agriculture input because it is readily available and mostly free.

${ }^{14}$ We categorize irrigation as an inexpensive cultivation method as its changes are mainly in the form of lifting water to the farm in studied areas. No new construction of dams, channels or other large-scale irrigation systems were observed in the field during the intervention period.
} 
tilizer and pesticides. All these farming methods and the usage of improved seeds were strongly recommended by the Model Farmer in their trainings to general farmers, except that the program cautiously promoted chemical fertilizer due to environmental concerns. For pesticides, the recommendation is to be aware about diseases and use Model Farmers' service for pesticide use if necessary.

We begin with analysis of the impact of the program on the adoption of improved cultivation methods promoted by BRAC. Regression results reported in Table 2 Column 1 - 4 show that compared with households residing in villages just above the 6 $\mathrm{km}$ distance cutoff, residing in villages within the threshold increases the adoption rates of manure by 4.5 percentage points, intercropping by 6 percentage points, crop rotation by 5.4 percentage points, and irrigation by 2.8 percentage points. Observational evidence from the field shows no new construction of dams and other large scale capital intensive irrigation systems. Thus, the increased irrigation is mainly through the often observed labor intensive effort of lifting water to the farm. All these results show that, given small compensations, Model Farmers are effective in promoting their neighbor's adoption of improved basic farming methods that require minimal monetary investments.

Both intercropping and crop rotation have been documented to reduce weed population density in the agronomy literature and are important components of weed management strategies (Liebman \& Dyck, 1993; Cléments, Weise \& Swanton, 1994). While weeding is also recommended in the agricultural training sessions, the increased practices of intercropping and crop rotation reduce weeding requirements. On net, the extension program significantly decreases the likelihood of weeding by 10.1 percentage points. Since weeding is a labor-intensive task, a reduction of necessary weeding time frees up farmers' labor for other productive activities. This is consistent with previous results, notably the increased irrigation practice by lifting water. In addition, households with decreased demand for agricultural labor may 
be more likely to send members for wage employment, which we will examine in the next subsection.

The training provided by Model Farmers not only promotes the adoption of improved cultivation methods, but also the usage of HYV seeds. Interestingly, the estimated impact of the program on the adoption rate of improved seed is minimal (Table 2 Column 8), regardless of improved access for general farmers and subsidy to local sellers (CAPs), which may or may not transfer to other farmers. The 2011 agricultural survey did not collect information on prices that the CAPs sell BRAC seeds; but another survey conducted one year later for a different sample collected these price data. The average per kg prices CAPs charged for maize and bean in the first season of 2012 (January-June, 2012) were 2888 USh and 2817 USh, respectively, which lie in the range of market prices, 2800-3000 USh. Thus, the subsidy to CAPs barely transfers to general farmers and has minimal impact on the overall adoption rate of HYV seeds, regardless of possible peer pressure by general farmers to pass along the subsidy. Note that the agricultural extension increases the seed purchase rate from BRAC by 5.7 percentage points (Table 2 Column 9), possibly due to advertising BRAC seeds in the training sessions. The increased seed purchase from BRAC and unchanged overall adoption suggest crowding out of the local supply, albeit while saving time and costs of travel to purchase seeds at market centers; so farmers may still benefit in this way. ${ }^{15}$ In addition, the effect of the extension program on the adoption rate of chemical fertilizer and pesticides are small and statistically insignificant. Again, these practices were not emphasized part of the program. Results are largely unchanged in robustness checks with different bandwidths ${ }^{16}$, with household-level controls (Table 2 Row 2) and using parametric regressions. ${ }^{17}$

\footnotetext{
${ }^{15}$ BRAC seeds may have higher average quality, but we lack comparative data to address this possibility.

${ }^{16}$ These estimates are reported in Table A2 of the online appendix.

${ }^{17}$ These estimates are reported in Table A6.
} 
Even though no more households eligible for the program started to use these advanced inputs, quantity used may change among existing adopters. To partially rule out this possibility, Table 3 Column 1 shows there is no statistically significant impact of the agricultural program on the total inputs costs. Assuming the prices of these inputs are not changed by the program (i.e. prices are smooth at the cutoff distance) and there is no reallocation of investment across inputs, the unchanged total monetary costs indicate no significant changes in quantity used for each of these advanced inputs. While the non-reallocation assumption cannot be fully tested using our data, the price smoothness assumption is likely to be valid given that the extension program does not subsidize fertilizer and pesticides, and the subsidized price for HYV seeds barely transferred to the general public as documented earlier. Thus, there may be other constraints impeding the farmers' adoption of these beneficial but expensive inputs: households may be credit constrained; this program focuses on women, but female farmers may not have control over households' financial decisions. ${ }^{18}$

\subsection{Food security}

BRAC's agricultural extension program may affect food security in at least three ways: decreased production costs (due potentially to subsidized seed prices); increased production value (due primarily to improved practices, and possibly marketing of non-subsistence crops); and increased wage income (due to time freed up from labor intensive farming practices, such as weeding). As shown earlier in Table

3 Column 1, there was minimal impact on the overall purchased productions costs. We then focus on the last two channels.

The survey covers information on the production of each crop for the last two sea-

\footnotetext{
${ }^{18}$ Jack (2013) provides a comprehensive literature review of possible constraints affecting farmer's adoption behavior.
} 
sons. We calculate the overall production value of major crops ${ }^{19}$ that are generally (though not always) reported in kilograms, and are then valued using contemporaneous market prices. ${ }^{20}$ These crops include common staple varieties, maize, beans, millet, groundnut, along with the leading cash crop, coffee.

The overall production values of these crops increase by $20.9 \%$ for households residing in villages eligible for BRAC's agricultural program (Table 3 Column 2). The large impact on production lies within the potential range obtained by agronomic field experiments. In particular, all these cultivation methods promoted by BRAC have been documented in the agronomy literature to significantly increase yield. For instance, intercropping cowpea and millet can increase the yield of millet by up to $103 \%$ (Hulet, Gosseye \& ILCA, 1986); application of carbonized and dried chicken manure boosts maize yield by up to $43 \%$ and soybean yield by approximately 30\% (Tagoe, Horiuchi \& Matsui, 2008). Moreover, Florentín (2010) finds that maize production increased by more than $30 \%$ after rotation with white lupine. In addition, Robins \& Domingo (1953) find that 6 to 8 days of water stress during pollination reduced maize yield by $50 \%$ in a field study in the U.S., which indicates a 100\% yield increase using irrigation during drought ( $>50 \%$ surveyed households in our sample reported that they experienced drought). These findings are further confirmed by Pandey, Maranville \& Admou (2000) using an experiment conducted in African context. In particular, they find that deficit irrigation during vegetative and reproductive periods reduces maize yields by up to $52 \%{ }^{21}$ Simply adding up the potential yield impact for each of these methods could explain around two thirds of the production increase. Note that these methods work in a complementary way and thus the total yield increase potential of these combined practices could be

\footnotetext{
${ }^{19}$ Major crops are defined as those grown by more than $5 \%$ of the households.

${ }^{20}$ Households report the quantity produced in various units (e.g. kilogram, bunch, sacks, basin).

${ }^{21}$ More references: see Reddy \& Willey (1981), Hulet, Gosseye \& ILCA (1986) and Li et al. (2001) for intercropping, Bullock (1992) and Berzsenyi, Győrffy \& Lap (2000) for crop rotation, Jokela (1992) and Matsi, Lithourgidis \& Gagianas (2003) for manure, and Mustek \& Dusek (1980) and Doorenbos \& Kassam (1979) for irrigation.
} 
significantly higher than revealed by this simple calculation.

Moreover, farmers may learn from the training about local soil quality and switch to crops that (they believe) are more profitable on their farm land. We observe a dramatic change in terms of crop composition grown for households covered by the program. ${ }^{22}$ Farmers eligible for the extension program are more likely to grow maize and beans, which were promoted by the program to be intercropped together, and are less likely to grow millet and groundnut. A greater share of these farmers is growing coffee, a popular cash crop that is mainly for sale in the market. Although the survey did not collect information on area cultivated by each crop, it is plausible that shifting towards more profitable crops could partially explain the production increase.

The agricultural training also provides detailed information about other productivityenhancing activities such as time and dosage of fertilizer and pesticide application, and labor saving harvest methods. In addition to the cultivation methods analyzed in this study, these non-monitored channels likely also contribute to the increase in the value of agricultural production. The very substantial estimated $20.9 \%$ increase in production value needs to be understood as the combined impact of these several channels of practices promoted by the program. Based on previous agronomic research, such large effects are very plausible; what is particularly remarkable is that an agricultural extension program could bring about a sufficient package of such change simultaneously so as to realize the huge impact on output value resulting from such low-cost activities.

As for employment, households covered by the agricultural program are 10.5 percentage points more likely to have at least a member working for wages (Table 3, Column 3). This effect may be due to the freeing up of off-farm work times as a result of utilizing the labor saving techniques promoted by BRAC. In treat-

\footnotetext{
${ }^{22}$ Details are presented in the online appendix Table A1.
} 
ment villages, households' total annual time working for wages increases by an estimated 166.7 hours, a considerable gain of about 7.6\% based upon the sample mean of 2187 hours for households with outside employment experience in the last 12 months. Since there is no statistically significant change in hourly wages received, the additional work time in the labor market raises wage income to the family. The dramatic estimated $36.4 \%$ increase in household savings (Table 3 Column 6) likely results from a combination of increased production value and greater outside wage income.

Given the unchanged advanced inputs usage, these income and savings benefits are likely driven by the adoption of improved cultivation methods. Note again that these improved techniques are not limited to the ones examined in this paper. Other efficiency-enhancing activities promoted by the training may contribute to the production gains as well. However, these non-monitored methods are also likely to incur little or no investment, a conclusion reinforced by the unchanged total production costs.

The agricultural extension program further increases per capita household's food consumption, as shown in Table 3 Column 5 (reported over the last 7 days) by about $17.1 \%$. When we look at a longer time horizon, the effect is even larger: the likelihood of having sufficient food to meet family needs increases by 28 percentage points over the previous year (Table 3 Column 6). In addition, households also reported which months of the last year they did not have enough food. We run the same local linear regression for each month to see the heterogeneous impact on reducing food insecurity over the agricultural cycle. Figure 5 plots the estimates for each month with 95\% confidence intervals. Overall, the agricultural program increased the proportion of households with sufficient food for every month within the one-year horizon. The magnitude of the impacts peak at June-July, 2011. According to the Uganda Food Security Outlook, while abundant rain led to above- 
average harvest in the second cropping season in 2010, the delayed rain in the first cropping season in 2011 delayed the harvest to July-August and put stress on food security for certain regions in Uganda (FEWSNET, 2010, 2011). The impacts of the agriculture extension program are the largest right before the harvest, during which the food situation is generally worst (as in most developing countries).

As widely noted, food availability is not sufficient for food security (Campbell, 1991; Maxwell, 1996; Barrett, 2002). Fortunately, the survey includes detailed self-reported data, which we use to examine impacts on food security. In the month prior to the survey, households eligible for the agricultural extension programs are 10.6 percentage points less likely to worry about insufficient food, 8.2 percentage points less likely to limit consumption varieties, 9.5 percentage points less likely to consume limited portions of food at each meal, and 14 percentage points less likely to skip meals, compared with control group households (Table 4). Taken together, these results confirm the positive impact of the extension program on improving food security among participating villages.

\subsection{Coping with shocks}

The methods households use to cope with shocks can serve as another measure of food security. Corresponding to the insufficient rain in the first cropping season of 2011, more than $40 \%$ of households reported that they experienced drought conditions. Overall, about $54 \%$ of households experienced at least one covariant shock, including drought, flood, pest attack, livestock epidemic, fire, or poor quality seeds in the village in the 6 months prior to the survey. ${ }^{23}$ Restricting the analysis to these households, Table 5 shows the impact of program eligibility on the usage of seven most reported shock-coping methods. As shown in Column 1, households in villages covered by the extension program are 14 percentage points more likely to

\footnotetext{
${ }^{23}$ There is no discontinuity in the incidence of shocks at the cutoff distance of $6 \mathrm{~km}$.
} 
use savings to cope with shocks, which corresponds to greater savings availability given the significantly increased savings documented earlier. Adjustment through savings is a preferred coping strategy as it should have a smaller effect on future production food security. A disadvantageous strategy, begging, is reduced by 6.5 percentage points for households covered by the program.

Both consumption smoothing and asset smoothing are considered unfavorable methods to cope with shocks (Barrett, 2002) as both may limit production capability is often at a cost of impaired future food security. Selling assets implies possible higher transaction costs than adjustment through savings (or credit); farmers may also face unfavorable terms as contemporaneous distress sales of assets by neighbors causes downward pressure on prices (Barrett, 2002). As documented in the literature, reducing consumption is not as unfavorable as asset smoothing, especially for the relatively rich. Zimmerman \& Carter (2003), Carter \& Lybbert (2012) and Janzen \& Carter (2013) have shown that wealthier farmers tend to reduce consumption as opposed to selling assets in the face of shocks. The agricultural program has been shown to enhanced farmers economic status via increased production and savings, and is expected to shift farmers from asset smoothing to consumption smoothing. Moreover, as the program also increases household food consumption (as documented earlier in this section), this leaves more room for consumption reduction while maintaining minimum nutritional levels. Consistently, farmers exposed to the program are 11.4 percentage points more likely to reduce consumption and are 5.4 percentage points less likely to sell assets during shocks.

To sum up, the agriculture extension services significantly improve food security. The results are consistent using different measures of food security. Results are also largely unchanged in robustness checks with different bandwidths, with additional controls, ${ }^{24}$ and with parametric specifications. ${ }^{25}$

\footnotetext{
${ }^{24}$ See Table A3, A4, and A5 in the online appendix.

${ }^{25}$ Table A6 in the online appendix shows the parametric regression results, allowing standard
} 


\section{CONCLUSION}

This paper examines the impact of a well-known NGO-designed and operated agriculture extension program for smallholder women farmers in Uganda. The BRAC Uganda program features two main components to promote improved technology use: training, and easier access to and affordability of HYV seeds.

In sum, we find the extension activities significantly increase farmers' use of improved cultivation methods that are relatively costless, but there is minimal impact on adoption of relatively expensive inputs including HYV seeds. Moreover, the program leads to improved farmers' food security in terms of quantity and variety of food consumed, meal frequency, and self-reported anxiety related to the availability of food.

Given the unchanged usage of expensive advanced inputs, we attribute the increased agricultural output simply to the adoption of inexpensive farming methods. These methods, most likely, are not limited to ones for which we have data in the survey. In particular, we note that the agricultural training also provides detailed information about specific such efficiency-enhancing activities as time and dosage of fertilizer and pesticides application, and labor saving harvest methods. These non-monitored methods are also likely to incur little or no investment, given the unchanged total production costs, and are topics for future research.

Note that our impact estimates are applicable for households living around the 6 $\mathrm{km}$ boundary from BRAC branches, which are located at or near at county centers; thus, although these are rural agricultural households, they have somewhat better

errors to be correlated within villages. The estimated impacts are consistent with results obtained from non-parametric local linear regressions overall. Although a few outcomes, such as the adoption of manure, lose statistical significance in parametric regressions, the sign and magnitudes are in line with local linear regression estimates in general. These discrepancies may arise from the fact that parametric regressions use observations further away from the cutoff. Moreover, local linear regressions put more weight on households near the cutoff distance, while parametric regression assign equal weight to each household. As detailed in Gelman \& Imbens (2014), local linear regression is preferred over parametric global polynomial methods. 
market access; so we cannot be confident about the external validity of the results for farmers in isolated or hard-to-reach areas. Moreover, the program was not fully nationally representative, because it did not operate in the semi-arid northern districts (a region with mostly one cropping season in a year and sparsely populated farming areas recovering from conflict); however, otherwise the program had a wide geographic coverage. In addition, the program did not include any interventions on the rural value chain; its focus was primarily on food security, so it is not clear that results extend to extension programs with a value chain emphasis.

Regardless of these limitations, the case of BRAC Uganda provides important insights into how agricultural extension services in sub-Saharan Africa can have a substantial positive effect on food security. A large literature indicates that the potential benefits of using advanced inputs are large. However, many constraints impede farmers from adopting these expensive inputs. In contrast, this paper has shown that the improvement of cultivation methods alone, which require minimal upfront monetary investment, can significantly increase production.

It may be that impacts on outcomes such as use of advanced inputs become apparent only after time to consolidate the more foundational improvements such as those identified in this study. In this sense, in countries such as Uganda, food security may need to be achieved in stages, with sequential support from extension services. The important policy question concerning whether extension and development assistance could be more cost-effective if different components are implemented in an sequence is left for future research. 


\section{REFERENCES}

Anderson, Jock R., and Gershon Feder. 2007. "Agricultural Extension." In Handbook of Agricultural Economics. Vol. 3, ed. Robert Evenson and Prabhu Pingali, Chapter 44, 2343-2378. Elsevier.

Bandiera, Oriana, and Imran Rasul. 2006. "Social Networks and Technology Adoption in Northern Mozambique." The Economic Journal, 116(514): 869-902.

Bank, World. 2008. World Development Report 2008: Agriculture for Development. World Bank.

Barrett, Christopher B. 2002. "Food Security and Food Assistance Programs." In Handbook of Agricultural Economics. Vol. 2, ed. Bruce L. Gardner and Gordon C. Rausser, Chapter 40, 2103-2190. Elsevier.

Barrett, Christopher B, Michael R Carter, and C Peter Timmer. 2010. "A Centurylong Perspective on Agricultural Development." American Journal of Agricultural Economics, 92(2): 447-468.

Barua, Proloy. 2011. "Assessment of the Short-Run Impact of BRAC's Agriculture and Livestock Programme in Uganda." BRAC International Working Paper Series.

BenYishay, Ariel, and Ahmed Mushfiq Mobarak. 2014. "Social Learning and Communication." National Bureau of Economic Research, Inc NBER Working Papers 20139.

Berzsenyi, Zoltan, Béla Győrffy, and DangQuoc Lap. 2000. "Effect of Crop Rotation and Fertilisation on Maize and Wheat Yields and Yield Stability in a Longterm Experiment." European Journal of Agronomy, 13(2): 225-244.

Bullock, Donald G. 1992. "Crop Rotation." Critical Reviews in Plant Sciences, 11(4): 309-326.

Campbell, Cathy C. 1991. "Food Insecurity: A Nutritional Outcome or a Predictor Variable?" The Journal of nutrition, 121(3): 408-415.

Carter, Michael R, and Travis J Lybbert. 2012. "Consumption Versus Asset Smoothing: Testing the Implications of Poverty Trap Theory in Burkina Faso." Journal of Development Economics, 99(2): 255-264.

Cléments, David R, Stephan F Weise, and Clarence J Swanton. 1994. "Integrated Weed Management and Weed Species Diversity." Phytoprotection, 75(1): 1-18.

Conley, Timothy G., and Christopher R. Udry. 2010. "Learning about a New Technology: Pineapple in Ghana." American Economic Review, 100(1): 35-69.

Davis, Kristin, Ephraim Nkonya, Edward Kato, Daniel Ayalew Mekonnen, Martins Odendo, Richard Miiro, and Jackson Nkuba. 2012. "Impact of Farmer Field Schools on Agricultural Productivity and Poverty in East Africa." World Development, 40(2): 402-413. 
Doorenbos, Jan, and Amir H Kassam. 1979. "Yield Response to Water." Food and Agriculture Organization of the United Nations FAO Irrigation and Drainage Paper 33.

Duflo, Esther, Michael Kremer, and Jonathan Robinson. 2011. "Nudging Farmers to Use Fertilizer: Theory and Experimental Evidence from Kenya." American Economic Review, 101(6): 2350-90.

FEWSNET. 2010. "UGANDA Food Security Outlook Update."

FEWSNET. 2011. "UGANDA Food Security Outlook Update."

Florentín, Miguel Angel. 2010. "Green Manure/Cover Crops and Crop Rotation in Conservation Agriculture on Small Farms." Integrated Crop Management, 12.

Gelman, Andrew, and Guido Imbens. 2014. "Why High-order Polynomials Should not be Used in Regression Discontinuity Designs." National Bureau of Economic Research, Inc NBER Working Papers.

Godtland, Erin, Elisabeth Sadoulet, Alain de Janvry, Rinku Murgai, and Oscar Ortiz. 2003. "The Impact of Farmer-Field-Schools on Knowledge and Productivity: a Study of Potato Farmers in the Peruvian Andes." University of California at Berkeley, Department of Agricultural and Resource Economics and Policy CUDARE Working Paper Series 963.

Hahn, Jinyong, Petra Todd, and Wilbert Van der Klaauw. 2001. "Identification and Estimation of Treatment Effects with a Regression-Discontinuity Design." Econometrica, 69(1): 201-209.

Herdt, Robert W. 2010. "Development Aid and Agriculture." , ed. Robert Evenson and Prabhu Pingali Vol. 4 of Handbook of Agricultural Economics, Chapter 63, 3253-3304. Elsevier.

Hulet, H, P Gosseye, and BP ILCA. 1986. "Effect of Intercropping Cowpea on Drymatter and Grain Yield of Millet in the Semi-Arid Zone of Mali." 379-396, I.

Imbens, Guido, and Karthik Kalyanaraman. 2012. "Optimal bandwidth choice for the regression discontinuity estimator." The Review of Economic Studies, rdr043.

Jack, B. Kelsey. 2013. "Constraints on the Adoption of Agricultural Technologies in Developing Countries." Agricultural Technology Adoption Initiative, J-PAL (MIT) and CEGA (UC Berkeley) Literature review 20139.

Janzen, Sarah A, and Michael R Carter. 2013. "After the Drought: The Impact of Microinsurance on Consumption Smoothing and Asset Protection." National Bureau of Economic Research.

Jokela, William E. 1992. "Nitrogen Fertilizer and Dairy Manure Effects on Corn Yield and Soil Nitrate." Soil Science Society of America Journal, 56(1): 148-154.

Kondylis, Florence, Valerie Mueller, and Siyao Zhu. 2014. "Seeing is Believing? Evidence from an Extension Network Experiment." 
Krishnan, Pramila, and Manasa Patnam. 2014. "Neighbors and Extension Agents in Ethiopia: Who Matters More for Technology Adoption?" American Journal of Agricultural Economics, 96(1): 308-327.

Lee, D., and T. Lemieux. 2010. "Regression Discontinuity Designs in Economics." Journal of Economic Literature, 48(2): 281-355.

Lee, D.S. 2008. "Randomized Experiments from Non-Random Selection in U.S. House Elections." Journal of Econometrics, 142(2): 675-697.

Liebman, Matt, and Elizabeth Dyck. 1993. "Crop Rotation and Intercropping Strategies for Weed Management." Ecological applications, 92-122.

Li, Long, Jianhao Sun, Fusuo Zhang, Xiaolin Li, Sicun Yang, and Zdenko Rengel. 2001. "Wheat/Maize or Wheat/Soybean Strip Intercropping: I. Yield Advantage and Interspecific Interactions on Nutrients." Field Crops Research, 71(2): 123137.

Liniger, Hanspeter, Rima Mekdaschi Studer, Christine Hauert, and Mats Gurtner. 2011. "Sustainable Land Management in Practice: Guidelines and Best Practices for Sub-Saharan Africa." Food and Agriculture Organization of the United Nations.

Matsi, Theodora, Anastasios S Lithourgidis, and Athanasios A Gagianas. 2003. "Effects of Injected Liquid Cattle Manure on Growth and Yield of Winter Wheat and Soil Characteristics." Agronomy Journal, 95(3): 592-596.

Maxwell, Daniel G. 1996. "Measuring Food Insecurity: the Frequency and Severity of 'Coping Strategies'." Food Policy, 21(3): 291-303.

McCrary, J. 2008. "Manipulation of the Running Variable in the Regression Discontinuity Design: A Density test." Journal of Econometrics, 142(2): 698-714.

Munshi, Kaivan. 2004. "Social Learning in a Heterogeneous Population: Technology Diffusion in the Indian Green Revolution." Journal of Development Economics, 73(1): 185-213.

Mustek, JT, and DA Dusek. 1980. "Irrigated Corn Yield Response to Water." Transactions of the ASAE, 23: 92-98.

Mutandwa, Edward, and JF Mpangwa. 2004. "An Assessment of the Impact of Farmer Field Schools on Integrated Pest Management Dissemination and Use: Evidence from Smallholder Cotton Farmers in the Lowveld Area of Zimbabwe." Journal of Sustainable Development in Africa, 6(2): 24-31.

Pandey, RK, JW Maranville, and A Admou. 2000. "Deficit Irrigation and Nitrogen Effects on Maize in a Sahelian Environment: I. Grain Yield and Yield Components." Agricultural Water Management, 46(1): 1-13.

Poghosyan, Meri. 2011. "Baseline Report for the Evaluation of BRAC Uganda's 'Microfinance Multiplied' Approach." BRAC Research Report. 
Porter, J. 2003. "Estimation in the Regression Discontinuity Model." Unpublished Manuscript, Department of Economics, University of Wisconsin at Madison, 5-19.

Reddy, MS, and RW Willey. 1981. "Growth and Resource Use Studies in an Intercrop of Pearl millet/Groundnut." Field Crops Research, 4: 13-24.

Robins, JS, and CE Domingo. 1953. "Some Effects of Severe Soil Moisture Deficits at Specific Growth Stages in Corn." Agronomy Journal, 45(12): 618-621.

Tagoe, Seth O, Takatsugu Horiuchi, and Tsutomu Matsui. 2008. "Effects of Carbonized and Dried Chicken Manures on the Growth, Yield, and N content of Soybean." Plant and soil, 306(1-2): 211-220.

UBOS, Uganda Bureau of Statistics. 2006. Uganda National Household Survey 2005-6. Report on Socio-economic Module. Uganda Bureau of Statistics, Kampala, Uganda.

UBOS, Uganda Bureau of Statistics. 2007. Uganda National Household Survey 2005-6. Report on Agriculture Module. Uganda Bureau of Statistics, Kampala, Uganda.

UBOS, Uganda Bureau of Statistics. 2010. 2010 Statistical Abstract. Uganda Bureau of Statistics, Kampala, Uganda.

Udry, Christopher. 2010. "The Economics of Agriculture in Africa: Notes toward a Research Program.” African Journal of Agricultural and Resource Economics, 5(1).

Zimmerman, Frederick J, and Michael R Carter. 2003. "Asset Smoothing, Consumption Smoothing and the Reproduction of Inequality under Risk and Subsistence Constraints." Journal of Development Economics, 71(2): 233-260. 
Figure 1: Surveyed Counties

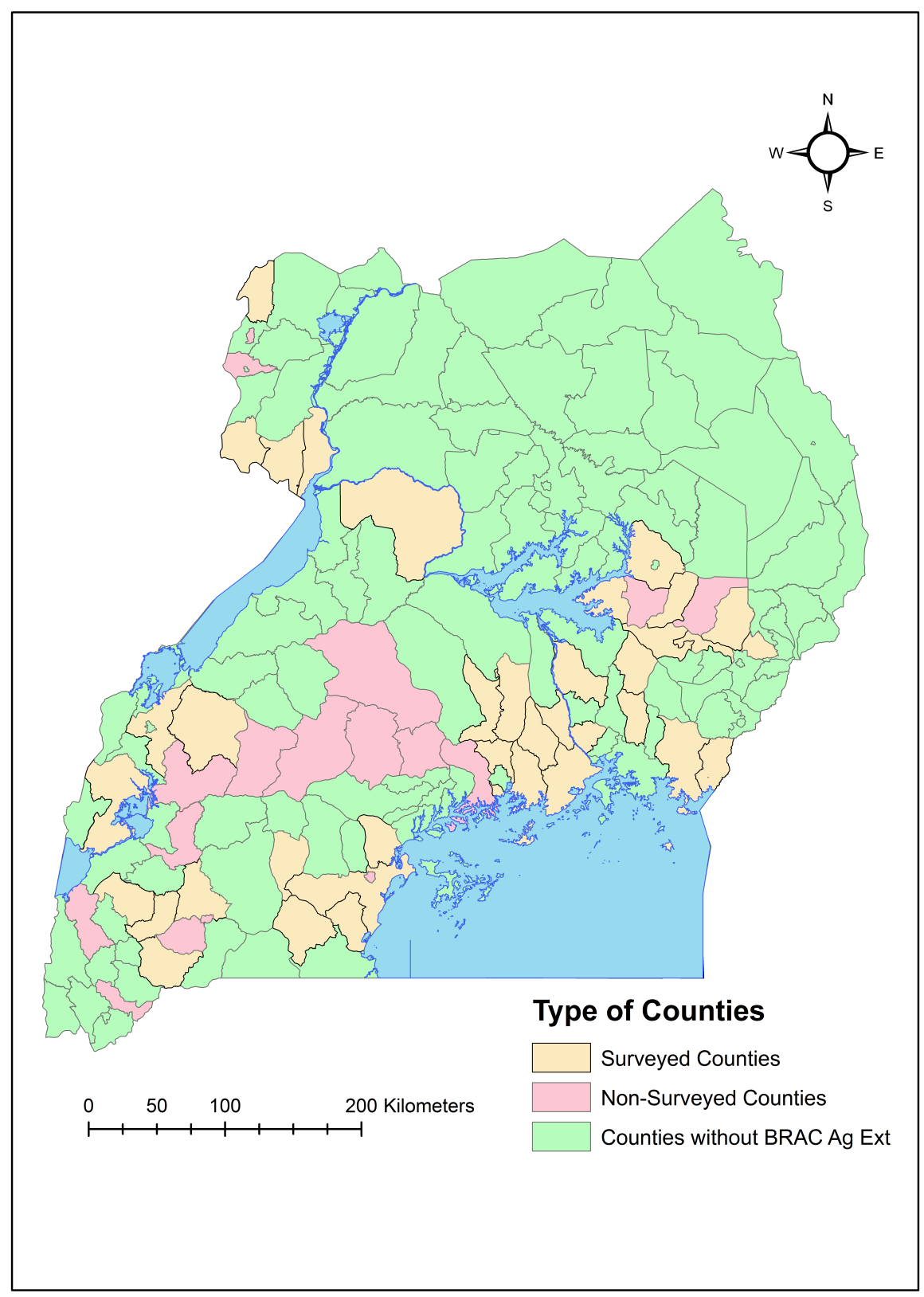

Notes: Figure shows the county coverage of the 2011 agriculture survey. Counties with BRAC's agricultural extension services include both "Surveyed Counties" and "Non-Surveyed Counties". 
Figure 2: Program Activities during the Six Months Prior to the Survey

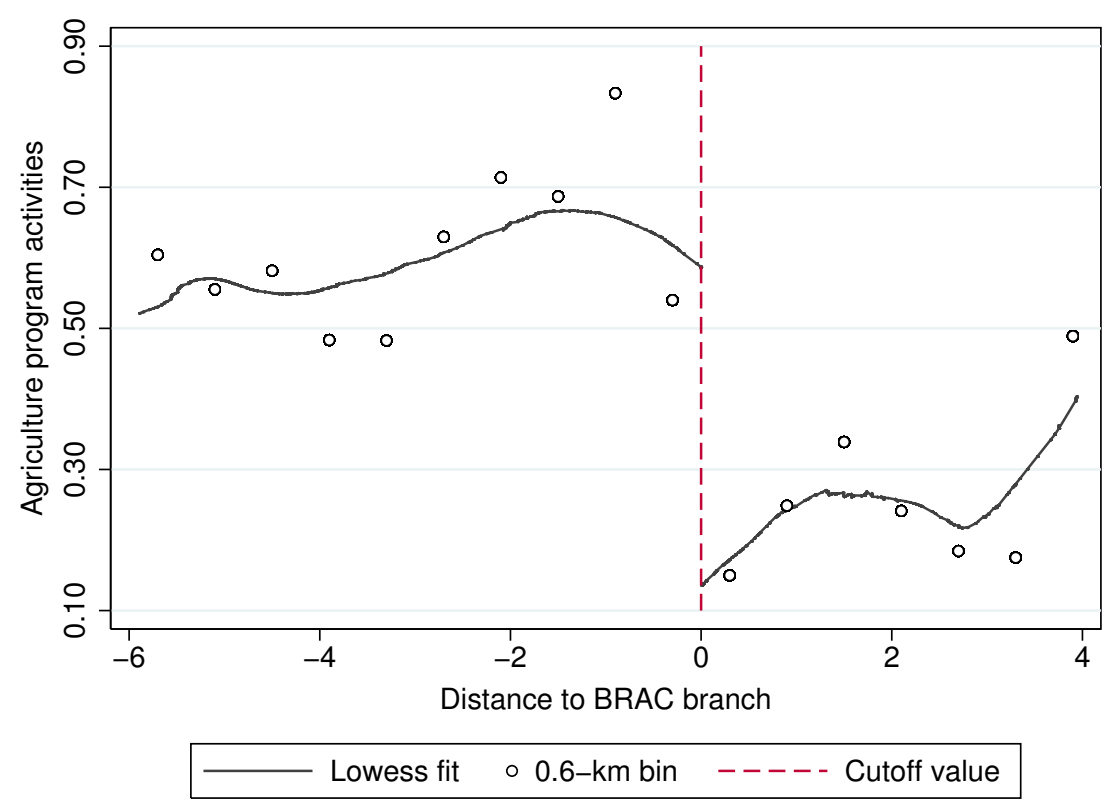

Notes: Figure shows the incidence of BRAC's agriculture extension program activities against distance to the nearest BRAC branch office. Distance is measured in $\mathrm{km}$ and is normalized with $6 \mathrm{~km}=0$.

Figure 3: Household Density against Distances to BRAC Branches

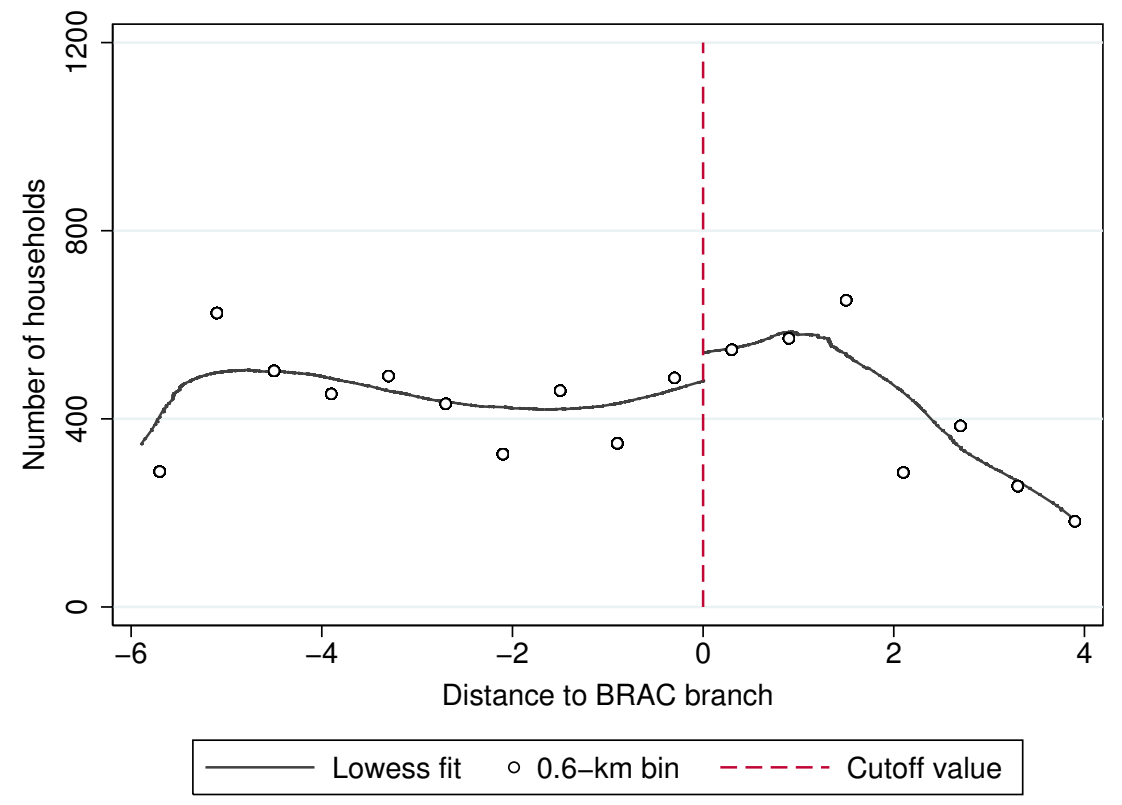

Notes: Figure shows the household density distribution against distance to the nearest BRAC branch office. Distance is measured in $\mathrm{km}$ and is normalized with $6 \mathrm{~km}=0$. 


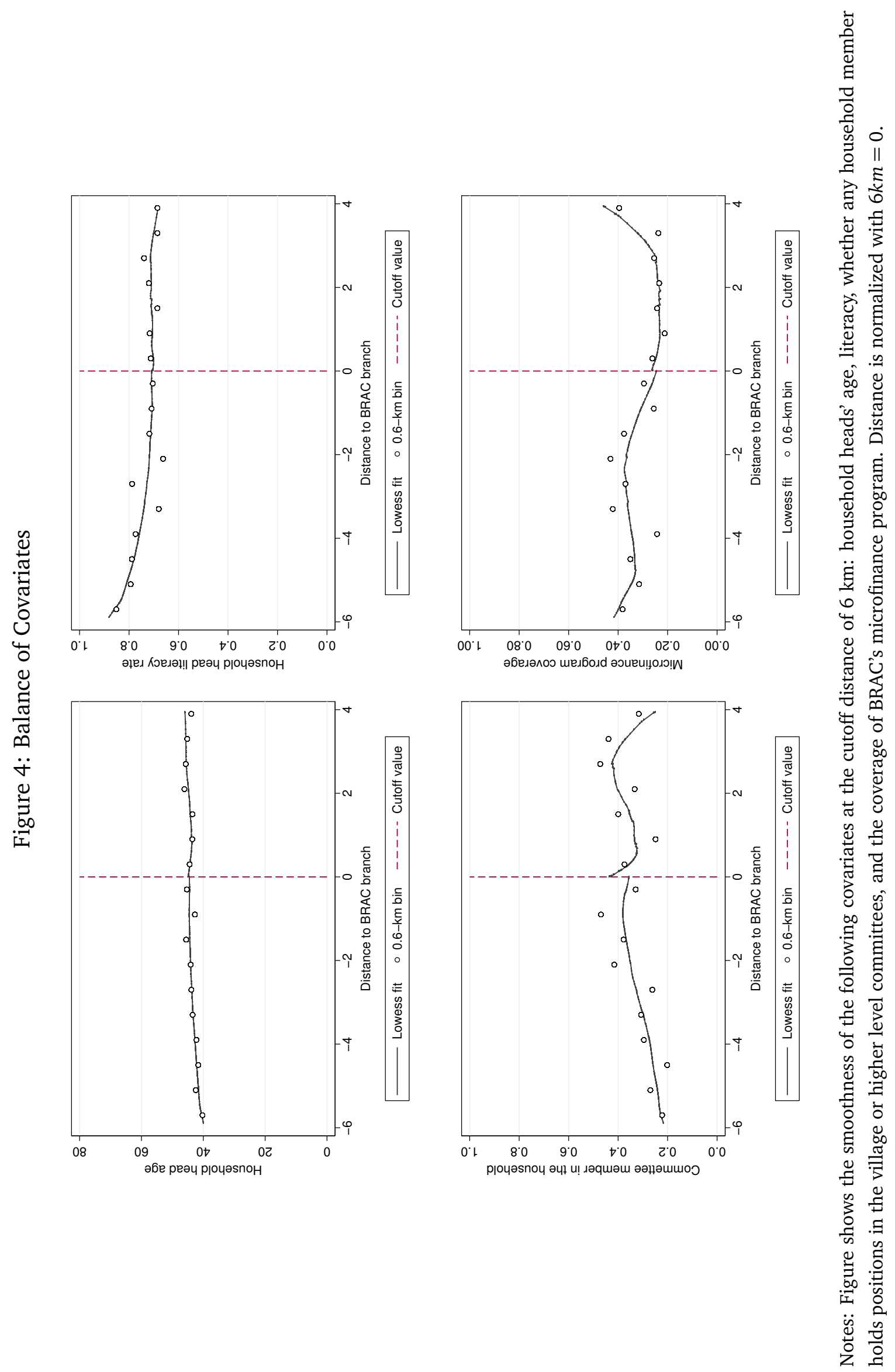


Figure 5: Program Effect on Food Sufficiency across Months

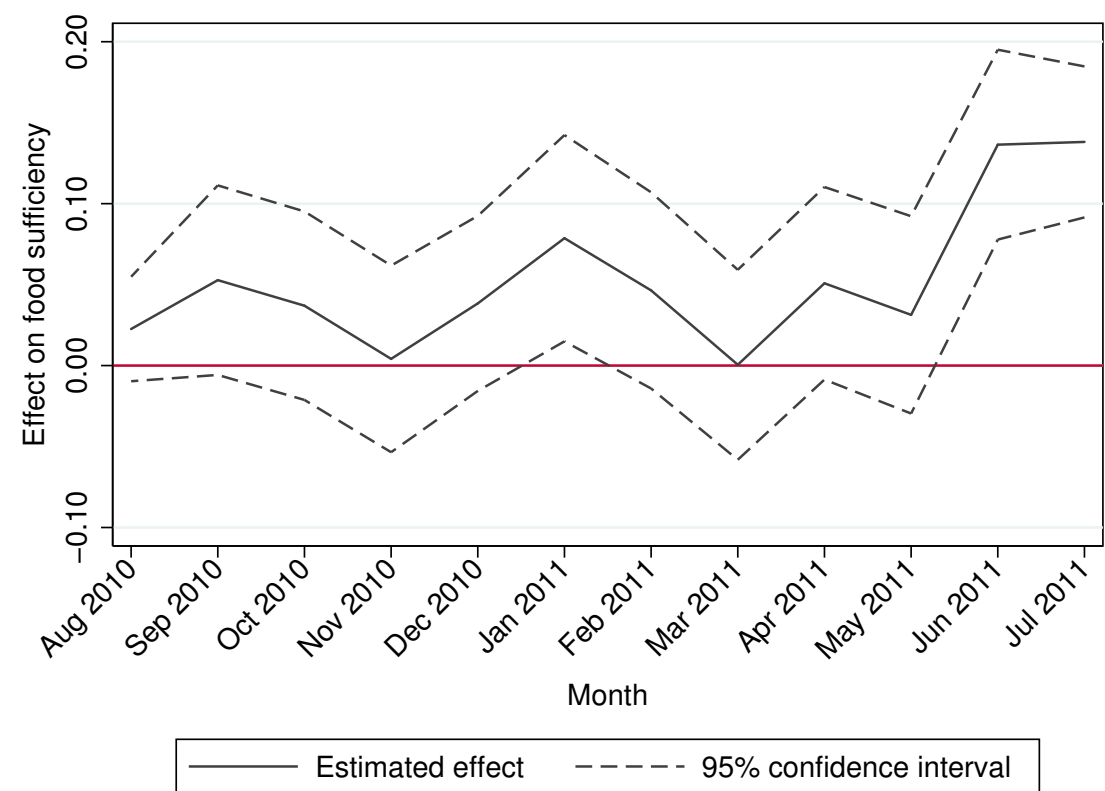

Notes: Figure shows the estimated impact of BRAC's agriculture extension program on the share of households with sufficient food for each of the 12 months prior to the survey. In general, in the absence of the intervention, the worst months for farmers are pre-harvest months of the main season, i.e. June and July. 
Table 1: Summary Statistics

\begin{tabular}{l|ccc}
\hline \hline & Mean & S.D. & $\mathrm{N}$ \\
\hline Household characteristics & & & \\
HH head age & 44.354 & 14.522 & 3368 \\
HH literacy & 0.704 & 0.457 & 3360 \\
HH member in council & 0.364 & 0.481 & 3403 \\
Modern techniques adoption & & & \\
Manure & 0.086 & 0.281 & 3103 \\
Intercropping & 0.813 & 0.389 & 3103 \\
Crop rotation & 0.823 & 0.381 & 3103 \\
Irrigation & 0.020 & 0.141 & 3103 \\
Weeding & 0.711 & 0.453 & 3103 \\
Fertilizer & 0.072 & 0.259 & 3103 \\
Pesticides & 0.130 & 0.337 & 3103 \\
HYV seeds (HYV) & 0.358 & 0.479 & 3103 \\
Production, emp. and savings & & & \\
Log production costs (in Ushs) & 10.681 & 1.168 & 2204 \\
Log production value (in Ushs) & 12.356 & 1.357 & 2978 \\
HH member work for salary & 0.232 & 0.422 & 3427 \\
Log household savings (in Ushs) & 11.282 & 1.642 & 2705 \\
Food security & & & \\
Log food cons. per capita & 9.109 & 0.957 & 3064 \\
(last 7 days, in Ushs) & & & \\
Food sufficiency (last year) & 0.212 & 0.409 & 3290 \\
Worry about food (last month) & 0.791 & 0.407 & 3408 \\
Limited variety (last month) & 0.822 & 0.382 & 3414 \\
Limited portion (last month) & 0.735 & 0.441 & 3411 \\
Skip meals (last month) & 0.641 & 0.480 & 3416 \\
\hline \hline
\end{tabular}

Note: Summary statistics are reported for the sample used in main estimations, including farmers residing in villages that are within $2.16 \mathrm{~km}$ on each side of the $6 \mathrm{~km}$ cutoff distance to the closest BRAC branch offices. 


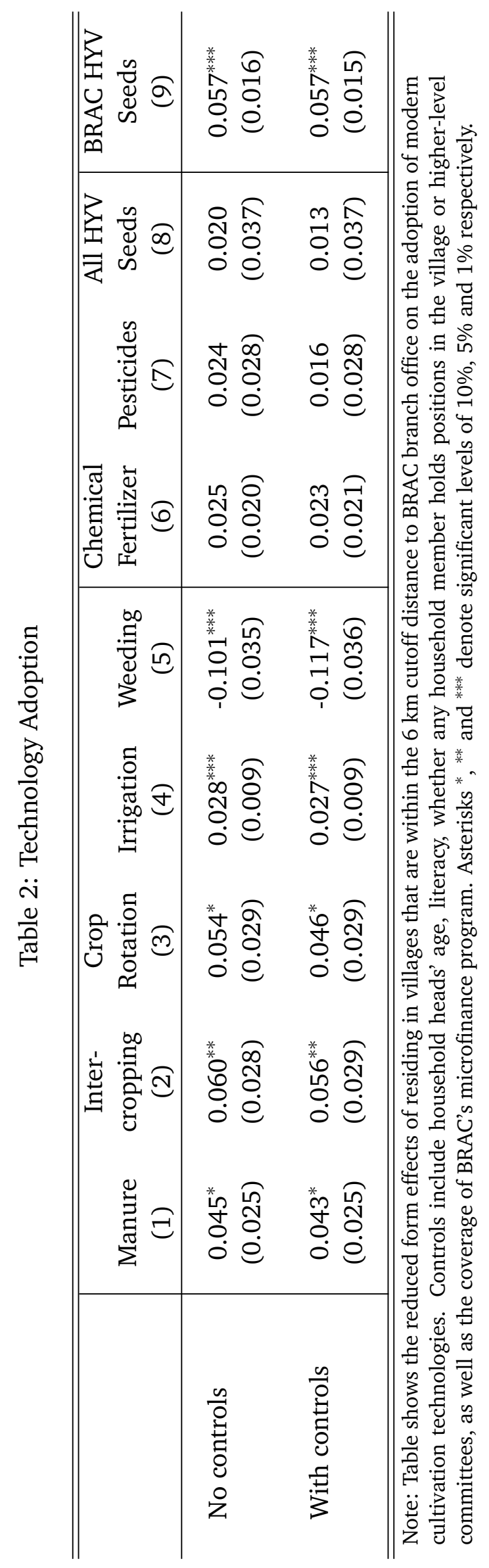




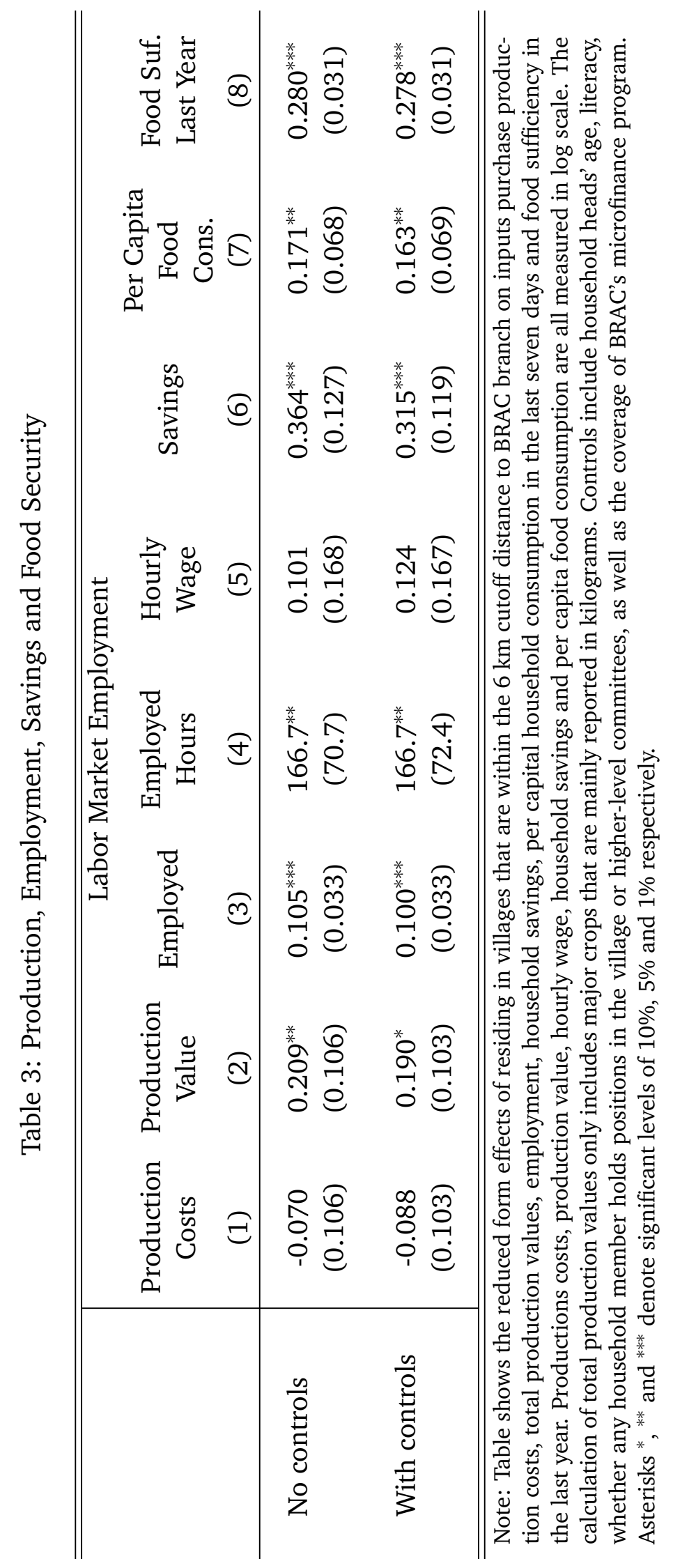




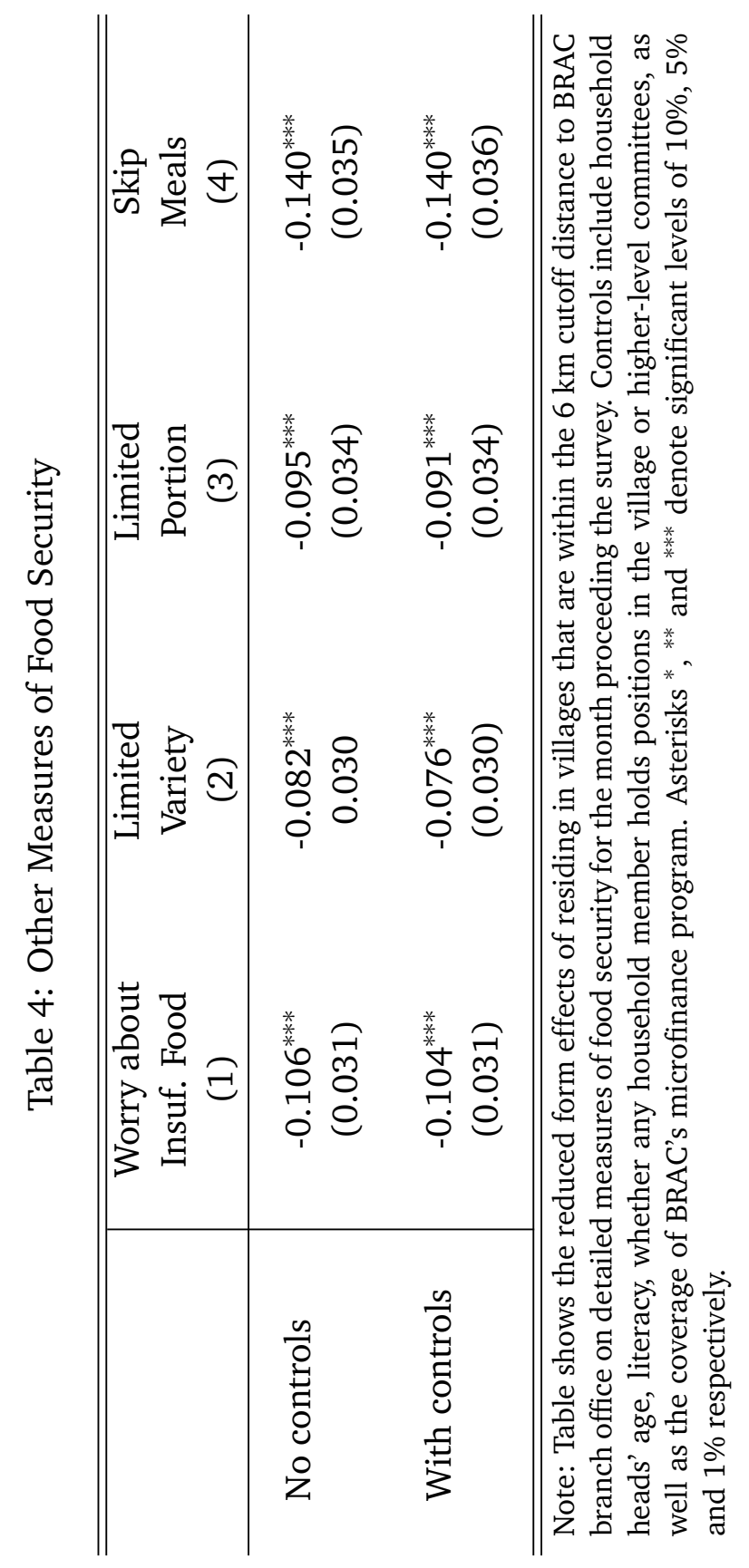




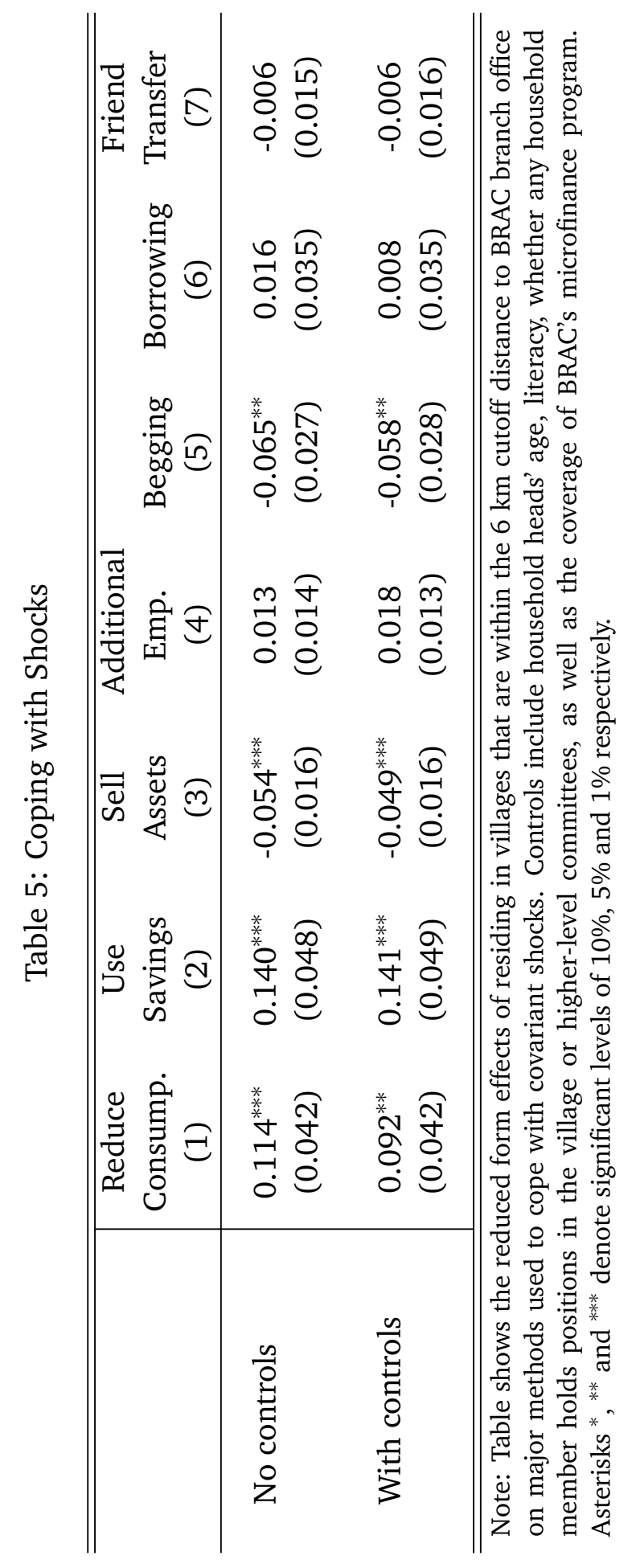




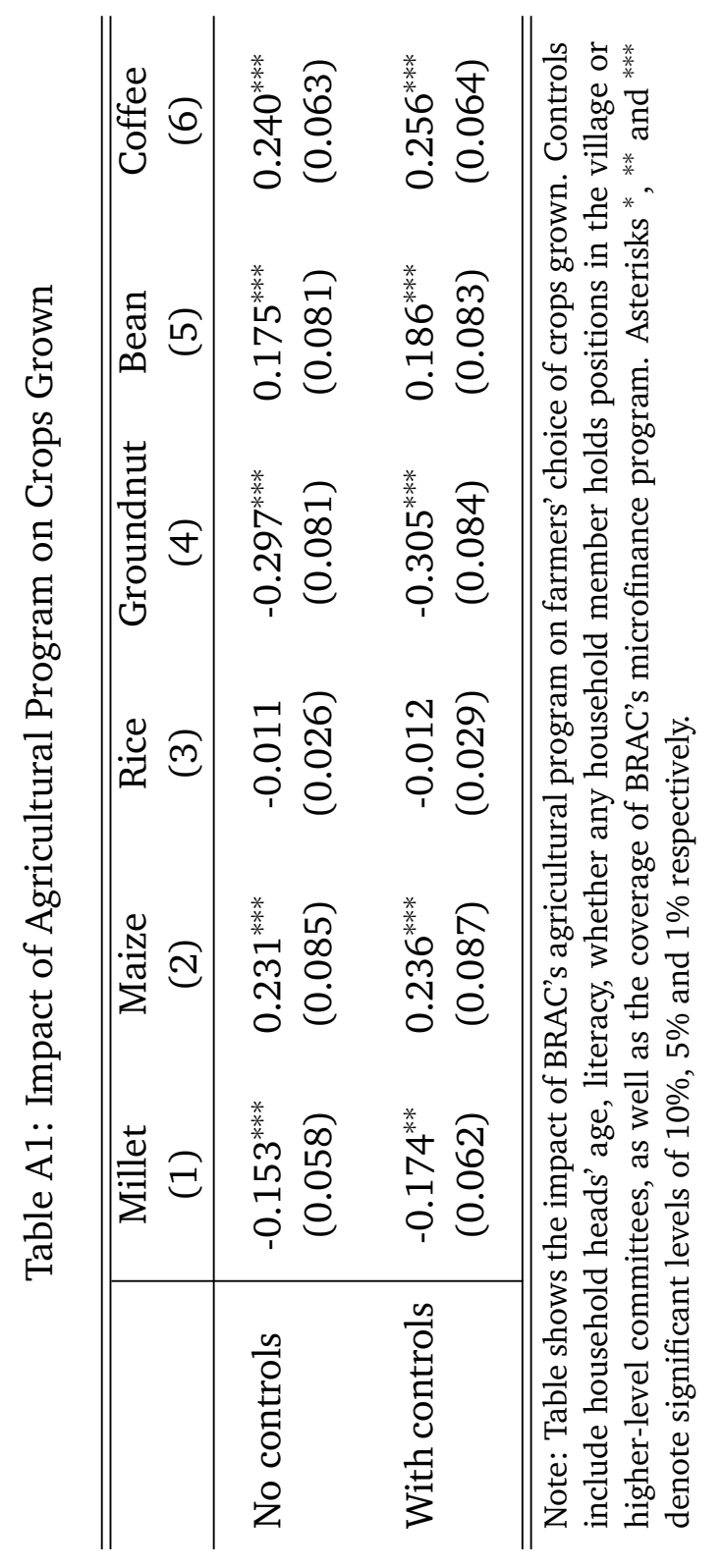

尝 


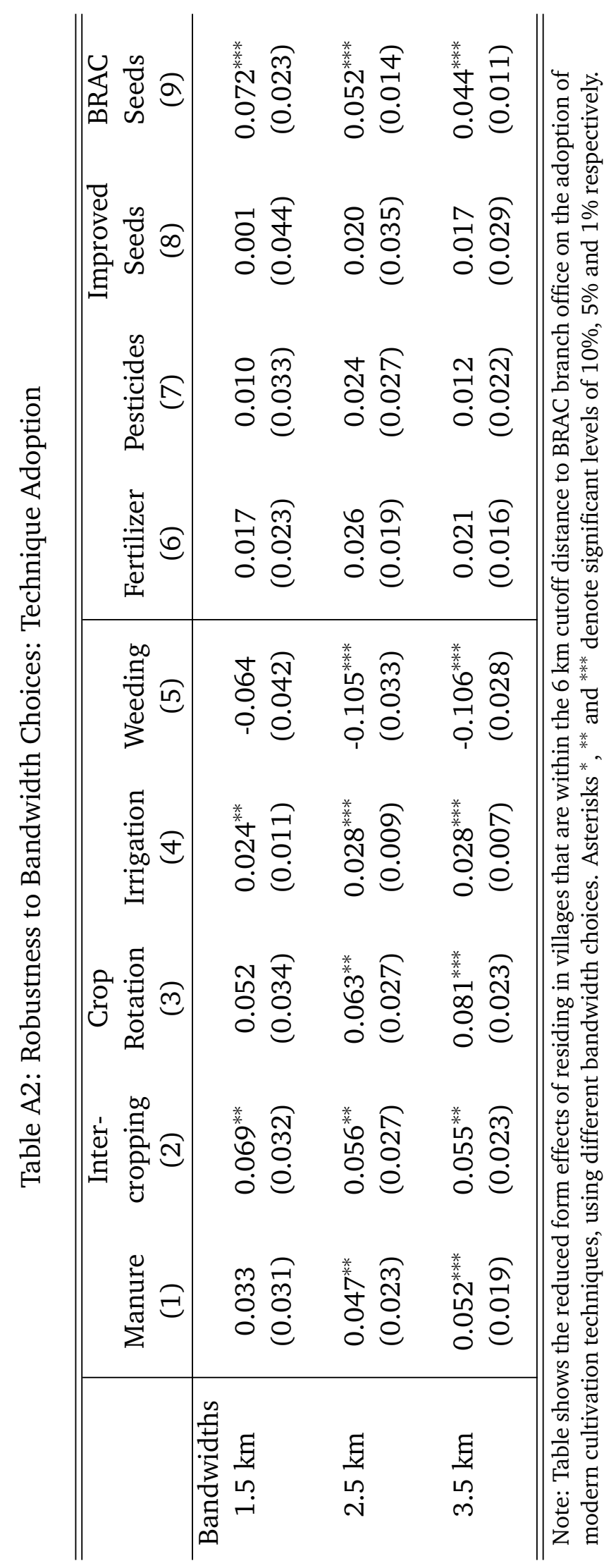




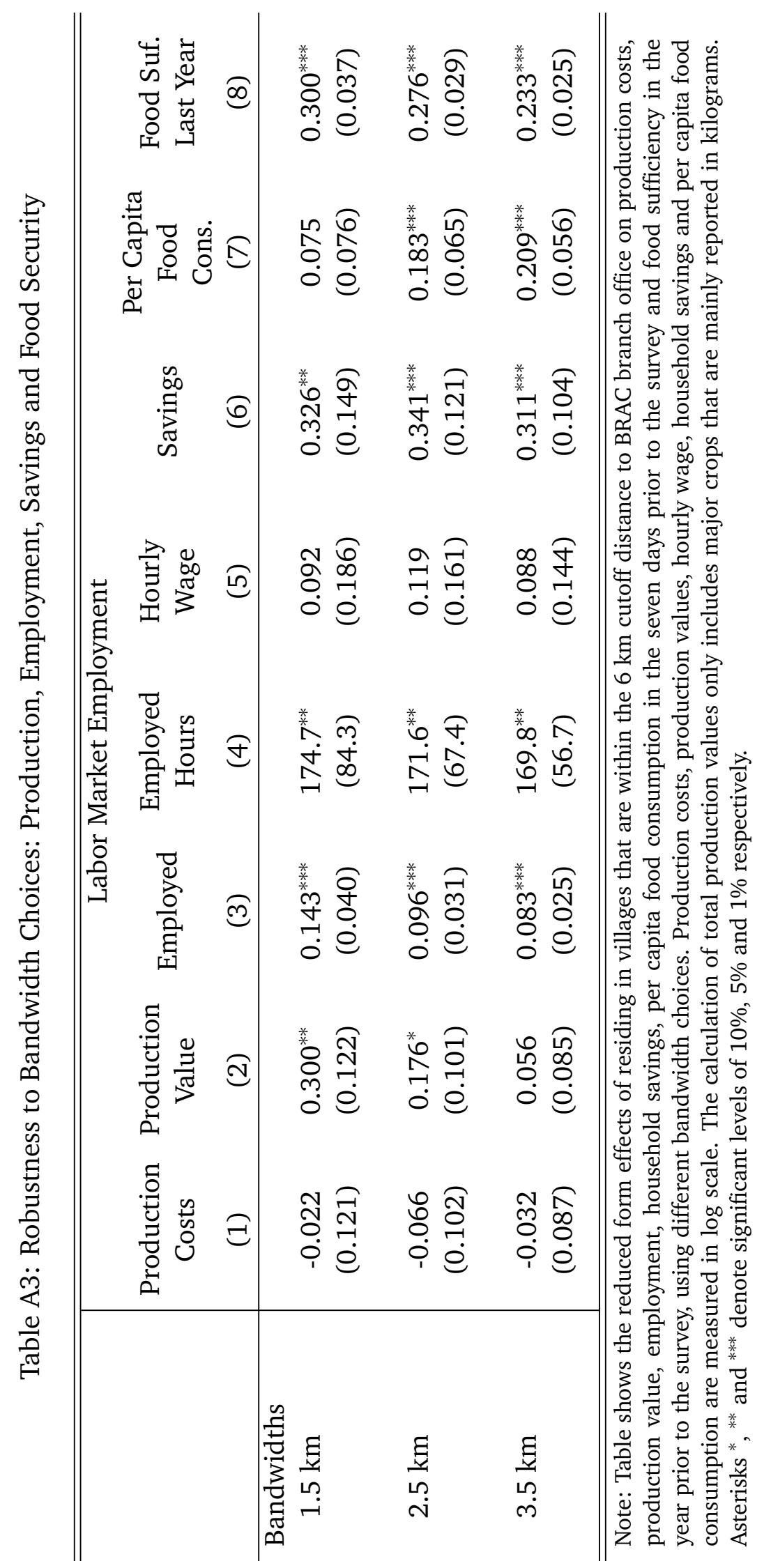




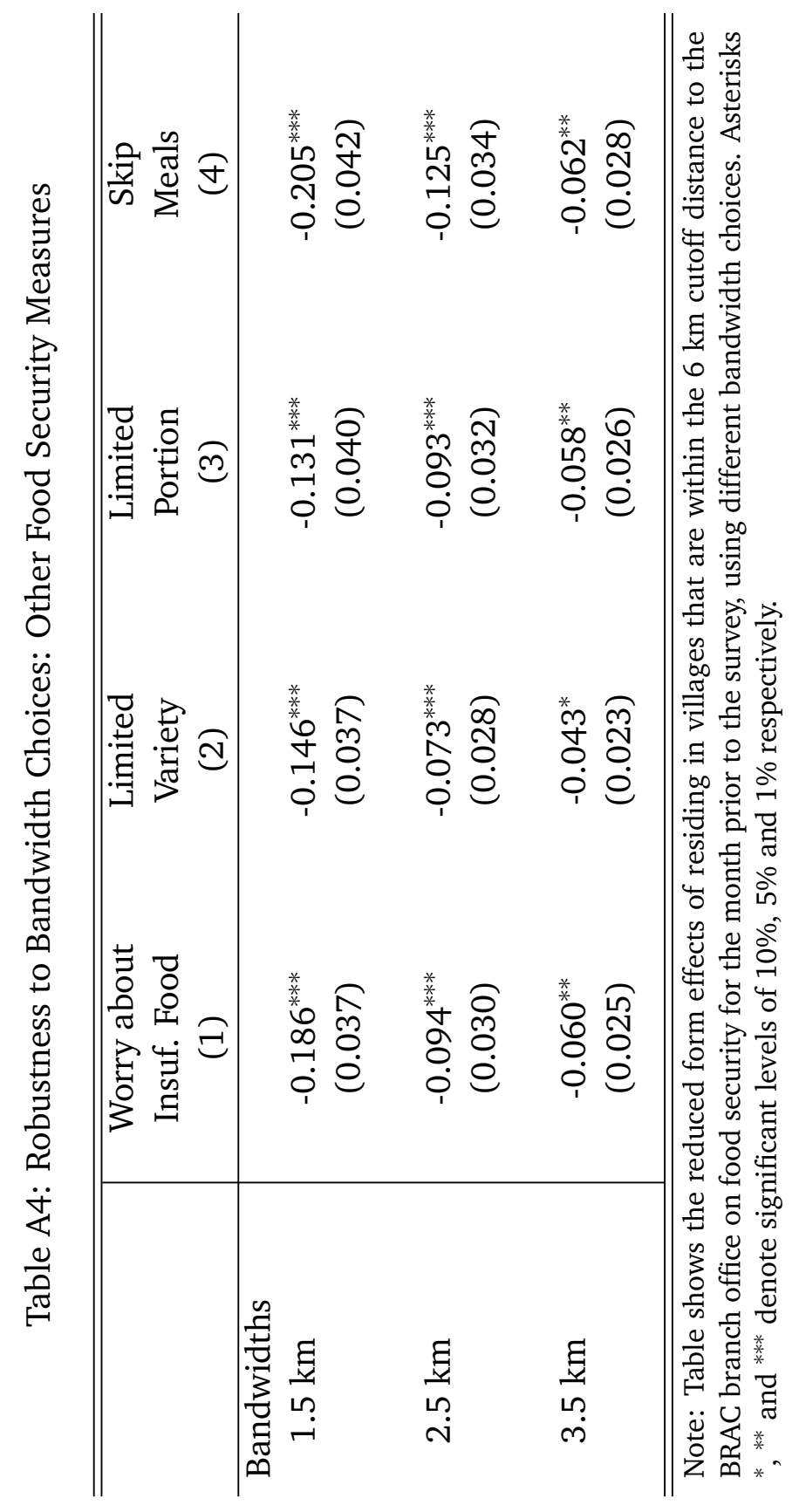




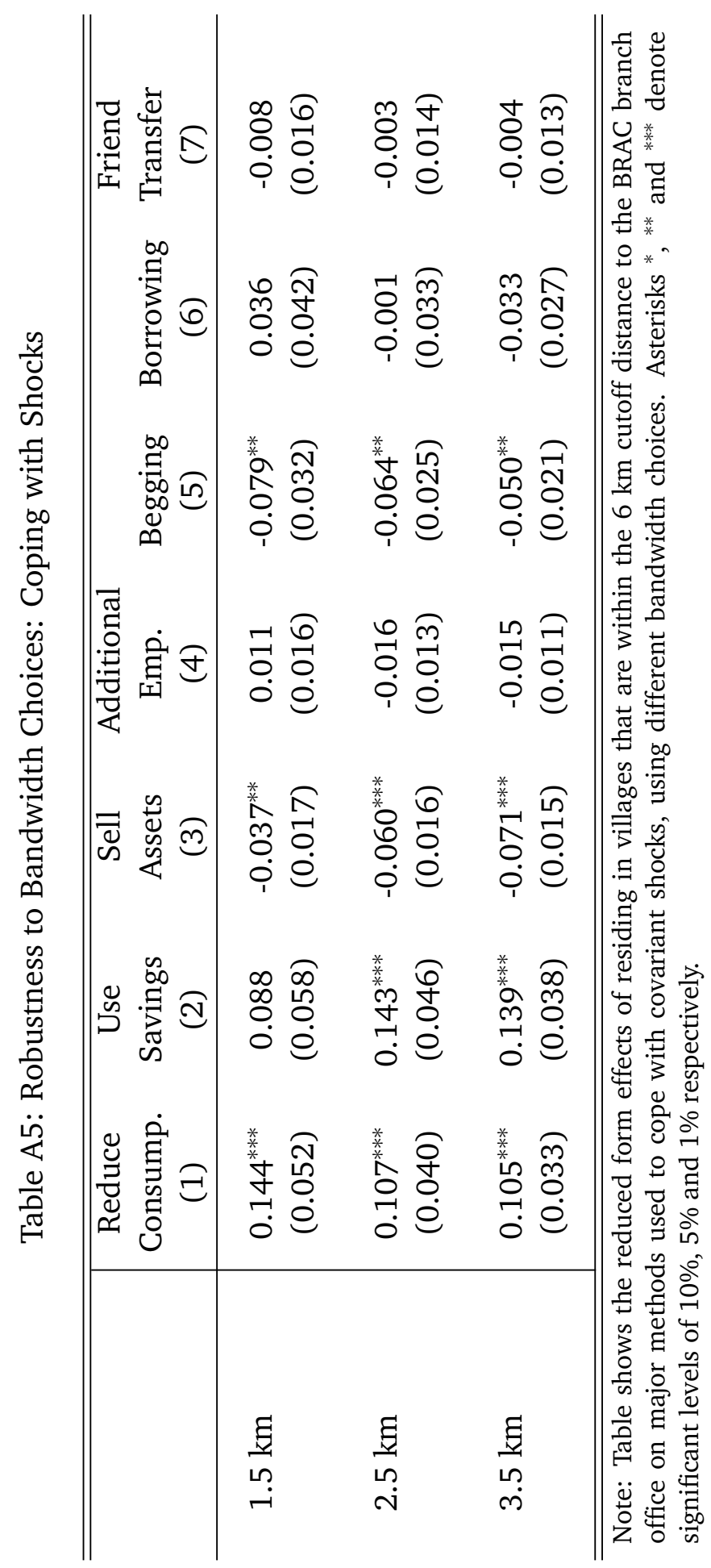




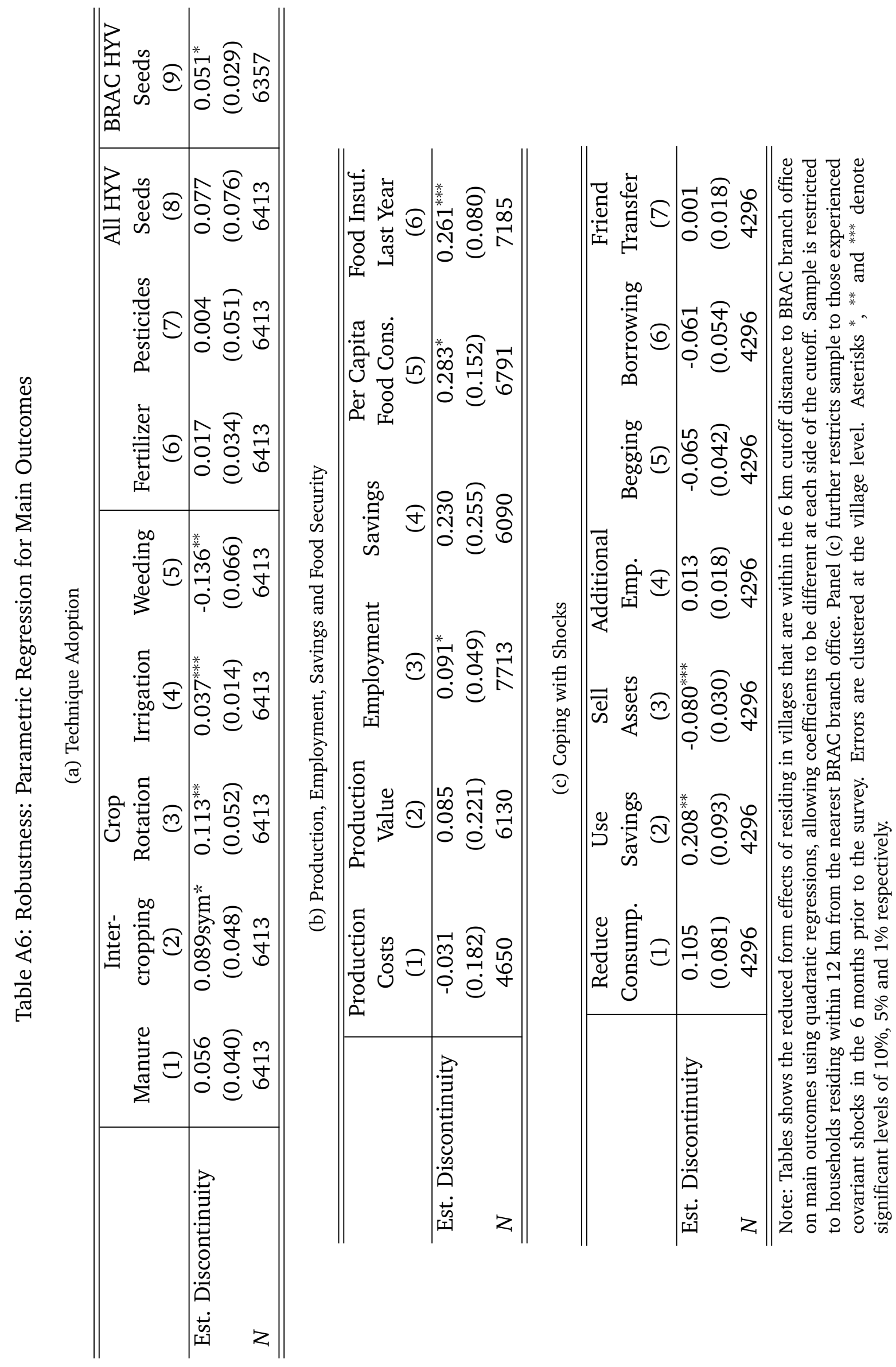




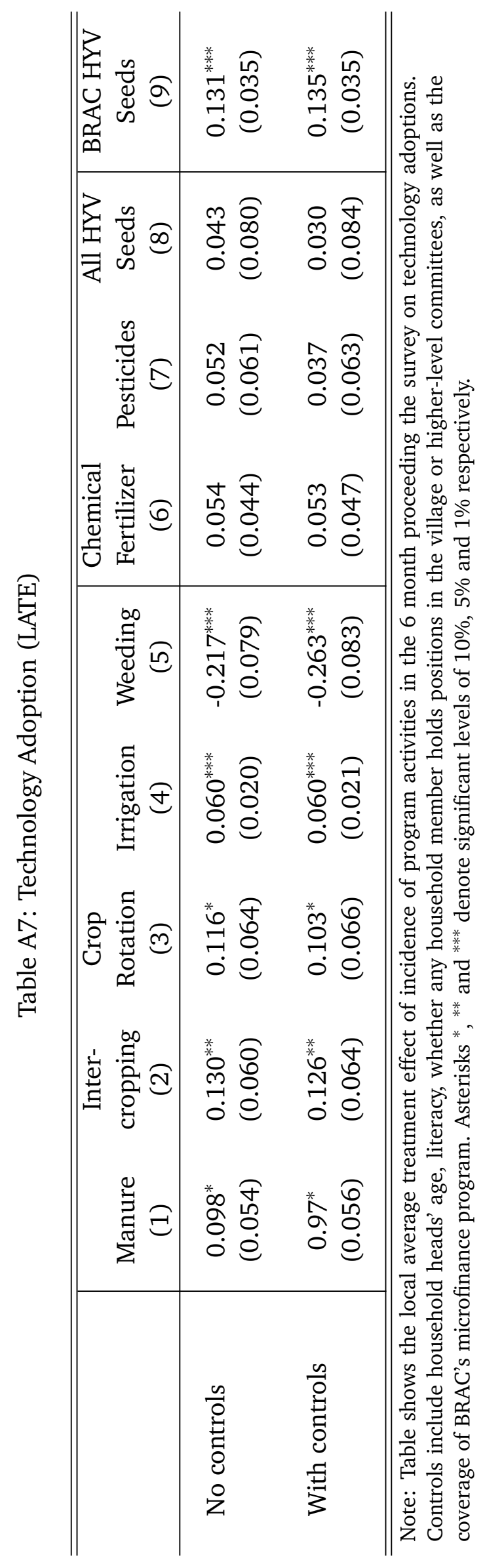




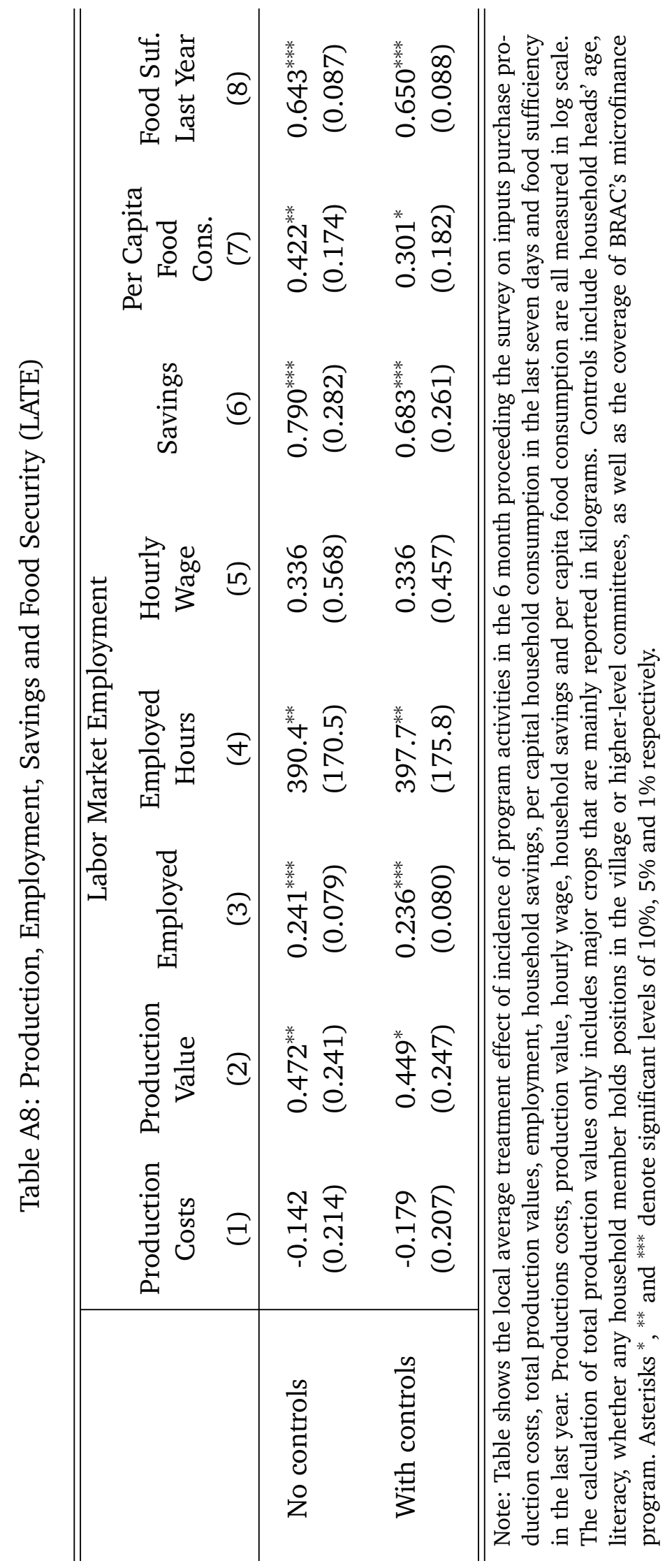




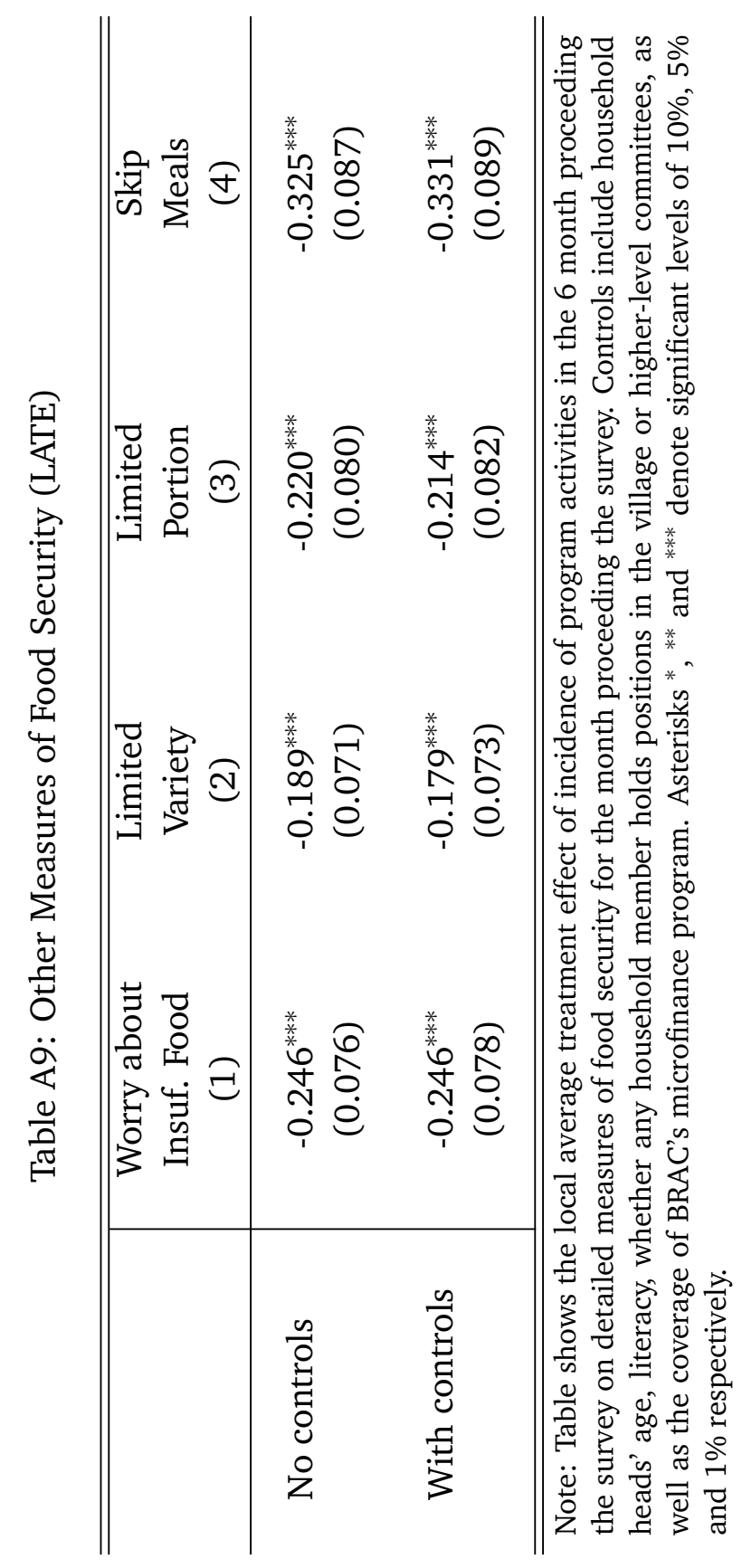




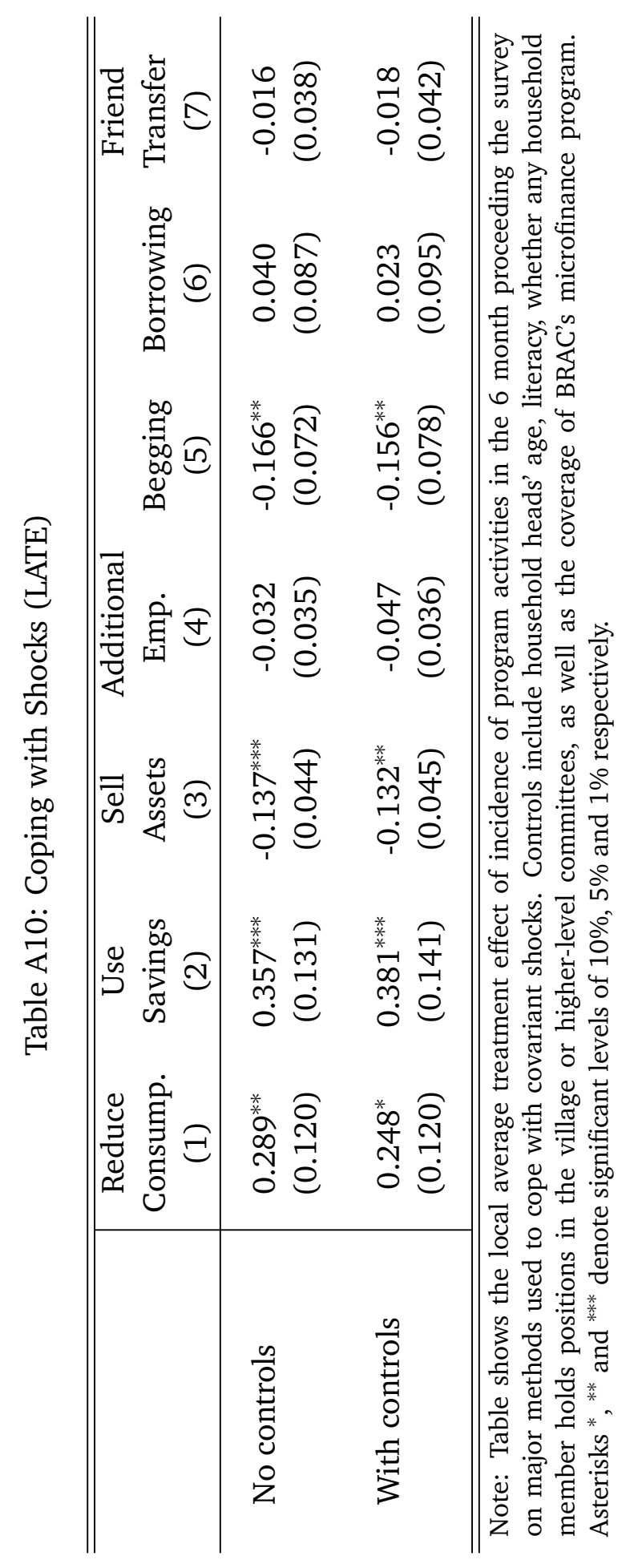

